University of Tennessee Health Science Center

UTHSC Digital Commons

\title{
An Update on Pharmaceutical Strategies for Oral Delivery of Therapeutic Peptides and Proteins
}

\author{
Nirnoy Dan \\ University of Tennessee Health Science Center
}

Follow this and additional works at: https://dc.uthsc.edu/dissertations

Part of the Pharmacy and Pharmaceutical Sciences Commons

\section{Recommended Citation}

Dan, Nirnoy (https://orcid.org/0000-0003-3335-9792), "An Update on Pharmaceutical Strategies for Oral Delivery of Therapeutic Peptides and Proteins" (2019). Theses and Dissertations (ETD). Paper 506. http://dx.doi.org/10.21007/etd.cghs.2019.0582.

This Thesis is brought to you for free and open access by the College of Graduate Health Sciences at UTHSC Digital Commons. It has been accepted for inclusion in Theses and Dissertations (ETD) by an authorized administrator of UTHSC Digital Commons. For more information, please contact jwelch30@uthsc.edu. 


\title{
An Update on Pharmaceutical Strategies for Oral Delivery of Therapeutic Peptides and Proteins
}

\begin{abstract}
Peptides and proteins are imperative for the human body and play crucial roles in governing various biochemical processes. Recent advances in molecular biology and biochemistry helped in understanding the role of these endogenous macromolecules in different pathological and disease conditions. Currently, small molecule drugs (<900dalton) in comparison to the therapeutic peptides and proteins-based drugs (TPP) dominate pharmaceutical market. However, the game is changing with the recent advances of biotechnological tools like recombinant DNA technology, solid phase protein synthesis etc., which enabled large-scale production of therapeutic peptides and proteins. The Success of Human Insulin, the first FDA approved commercial recombinant protein based therapeutic in 1982, revolutionized the field of TPPs. The number of FDA approved TPPs reached about to 239 in 2017 compared to where it was only $\sim 130$ in 2008. Rapid progress in this sector can be attributed to several advantages of proteins and peptides over small molecule drugs both financially and clinically. From a clinical perspective, proteins and peptides are inherently more specific to the target site than the small molecules drugs, which lead to less interferences with normal biological system of the patient and caused minimal off-target side effects. A handful of proteins which are used for different clinical complications are less immunogenic because they are produced in the body naturally. Furthermore, proteins and peptides also take part in several complex and complicated biological processes, which is difficult to be to be mimicked by the small molecule drugs. From a financial standpoint, median total pre-market development times were shorter for biologics (10.6 years) than the small molecules drugs (12.6 years) estimated using Merck Index. In 2009, US Congress passed the Biologics Price Competition and Innovation Act (BPCIA) which gave new biologics 12 years of guaranteed exclusivity. The most commonly utilized routes for administering TPPs are I.V, I.P or I.M injections, which largely suffer from patient compliances. There are 350 TPPs under clinical development and among them only 2 are given orally which is Interferon- $\alpha$ and Human growth hormone. Currently, most efforts in both industry and academia are centered around enhancing bioavailability of orally administered TPPs which typically are less than $1 \%$. Oral administration is the non-invasive, most preferred route of drug administration for the patients. Furthermore, oral dosage forms are cheaper to manufacture as well as to administer, because they do not need to be produced under sterile conditions or administered in clinics. However, unfavorable physicochemical characteristics of TPPs like high molecular weight, hydrophilicity, poor stability in the physiological conditions, short biological half-life, low permeability through the epithelial barrier in the small intestine put up a massive barrier in the development of orally available dosage forms of TPPs. In this review, we will discuss the challenges associated with oral delivery of TPPs and the ongoing efforts to solve them.
\end{abstract}

\section{Document Type}

Thesis

\section{Degree Name}

Master of Science (MS)

\section{Program}

Pharmaceutical Sciences

Research Advisor

Hassan Almoazen, Ph.D. 


\section{Keywords}

Biologics Delivery, Formulation, Oral Delivery, Proteins and Peptides

\section{Subject Categories}

Medicine and Health Sciences | Pharmacy and Pharmaceutical Sciences 
MASTER OF SCIENCE THESIS

\section{An Update on Pharmaceutical Strategies for Oral Delivery of Therapeutic Peptides and Proteins}

Author:

Nirnoy Dan
Advisor:

Hassan Almoazen, Ph.D.

A Thesis Presented for The Graduate Studies Council of

The University of Tennessee Health Science Center in Partial Fulfillment of the Requirements for the Master of Science degree from The University of Tennessee

$$
\text { in }
$$

Biomedical Sciences: Molecular and Systems Pharmacology College of Graduate Health Sciences 
Copyright (C) 2019 by Nirnoy Dan. All rights reserved. 


\section{DEDICATION}

To my respected parents, Mrs. Swapna Dan and Mr. Nilachal Dan, and my grandparents Mrs. Madhuri Dikpati and Mr. Laxmi Narayan Dikpati

for their unconditional love, inspiration and constant encouragement. 


\section{ACKNOWLEDGEMENTS}

I would first like to thank my advisor Dr. Hassan Almoazen. The door to Prof. Almoazen's office was always open whenever I had a question about my research or writing. He consistently allowed this paper to be my own work and steered me in the right the direction whenever he thought I needed it. I am truly thankful to him for the opportunities, motivation, guidance and support he gave to me throughout the research period.

I would also like to thank my committee members Drs. Duane D. Miller and Isaac O. Donkor. Without their passionate participation and input, the validation survey could not have been successfully conducted.

Finally, I must express my very profound gratitude Department of Pharmaceutical Sciences and College of Graduate health Sciences, UTHSC for their administrative and financial support. 


\begin{abstract}
Peptides and proteins are imperative for the human body and play crucial roles in governing various bio-chemical processes. Recent advances in molecular biology and biochemistry helped in understanding the role of these endogenous macromolecules in different pathological and disease conditions. Currently, small molecule drugs ( $<900$ dalton) in comparison to the therapeutic peptides and proteins-based drugs (TPP) dominate pharmaceutical market. However, the game is changing with the recent advances of biotechnological tools like recombinant DNA technology, solid phase protein synthesis etc., which enabled large-scale production of therapeutic peptides and proteins. The Success of Human Insulin, the first FDA approved commercial recombinant protein based therapeutic in 1982, revolutionized the field of TPPs. The number of FDA approved TPPs reached about to 239 in 2017 compared to where it was only $\sim 130$ in 2008.
\end{abstract}

Rapid progress in this sector can be attributed to several advantages of proteins and peptides over small molecule drugs both financially and clinically. From a clinical perspective, proteins and peptides are inherently more specific to the target site than the small molecules drugs, which lead to less interferences with normal biological system of the patient and caused minimal off-target side effects. A handful of proteins which are used for different clinical complications are less immunogenic because they are produced in the body naturally. Furthermore, proteins and peptides also take part in several complex and complicated biological processes, which is difficult to be to be mimicked by the small molecule drugs. From a financial standpoint, median total pre-market development times were shorter for biologics (10.6 years) than the small molecules drugs (12.6 years) estimated using Merck Index. In 2009, US Congress passed the Biologics Price Competition and Innovation Act (BPCIA) which gave new biologics 12 years of guaranteed exclusivity.

The most commonly utilized routes for administering TPPs are I.V, I.P or I.M injections, which largely suffer from patient compliances. There are $\sim 350$ TPPs under clinical development and among them only 2 are given orally which is Interferon- $\alpha$ and Human growth hormone. Currently, most efforts in both industry and academia are centered around enhancing bioavailability of orally administered TPPs which typically are less than $1 \%$. Oral administration is the non-invasive, most preferred route of drug administration for the patients. Furthermore, oral dosage forms are cheaper to manufacture as well as to administer, because they do not need to be produced under sterile conditions or administered in clinics. However, unfavorable physicochemical characteristics of TPPs like high molecular weight, hydrophilicity, poor stability in the physiological conditions, short biological half-life, low permeability through the epithelial barrier in the small intestine put up a massive barrier in the development of orally available dosage forms of TPPs. In this review, we will discuss the challenges associated with oral delivery of TPPs and the ongoing efforts to solve them. 


\section{TABLE OF CONTENTS}

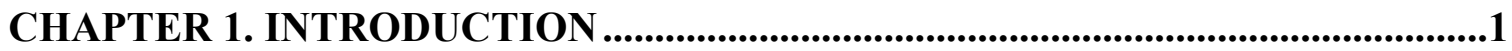

\section{CHAPTER 2. CHALLENGES ASSOCIATED WITH ORAL DELIVERY OF}

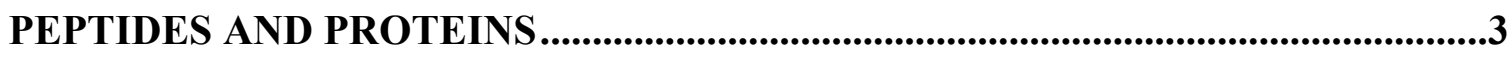

Enzymatic Barriers of the Digestive System ............................................................

Transport Across the Epithelial Membrane in The Small Intestine..................................3

\section{CHAPTER 3. STRATEGIES FOR ENHANCING ORAL DELIVERY OF} PROTEINS AND PEPTIDES....................................................................................6

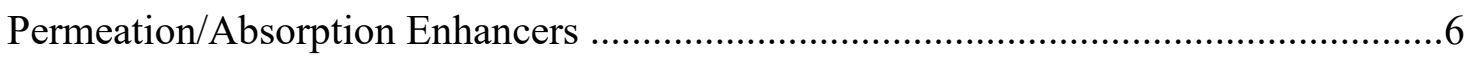

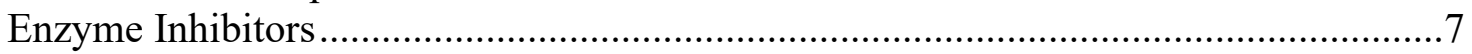

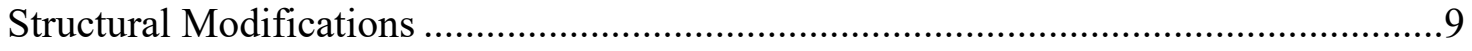

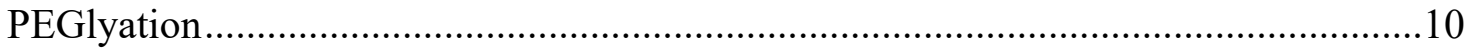

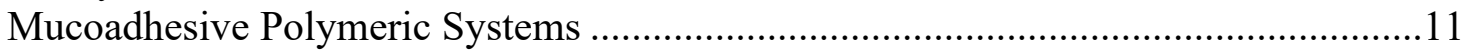

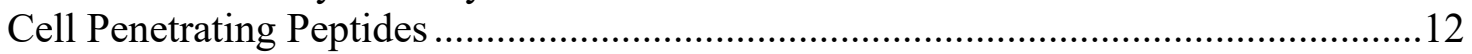

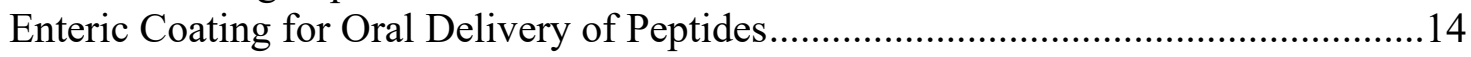

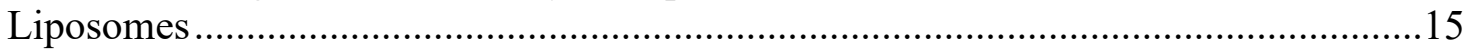

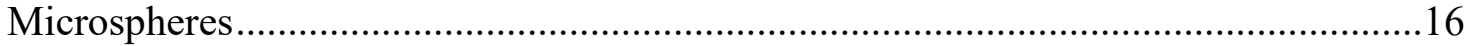

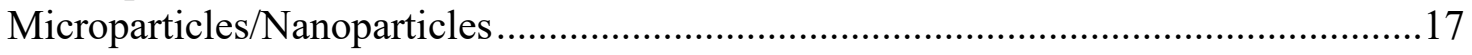

\section{CHAPTER 4. CLINICAL INVESTIGATION OF ORAL PEPTIDES AND}

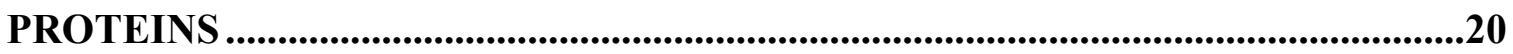

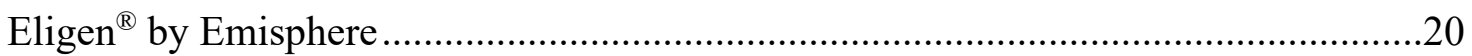

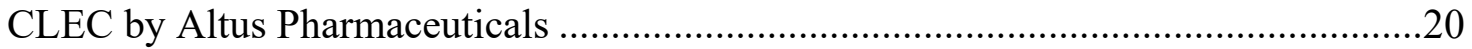

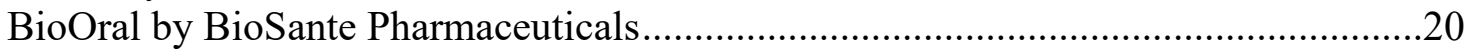

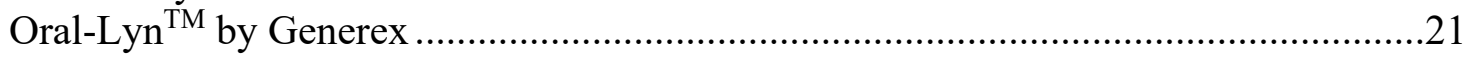

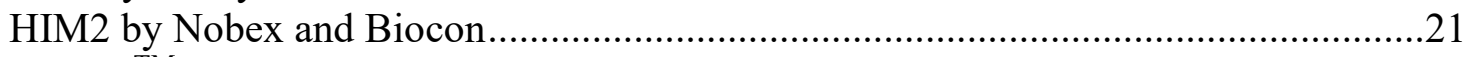

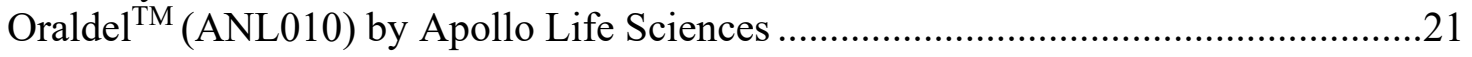

AI-401 by Eli-Lilly and Autoimmune Inc. ..............................................................22

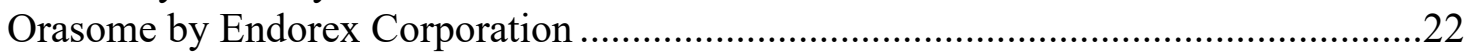

GIPET $^{\circledR}$ by Merrion Pharma and Novo Nordisk ………........................................22

Oramed by Oramed Pharmaceuticals .............................................................................22

Peptelligence ${ }^{\mathrm{TM}}$ from Unigene Laboratories, Enteris Biopharma..................................23

CHAPTER 5. CONCLUSIONS AND FUTURE DIRECTIONS ..................................24

LIST OF REFERENCES .....................................................................................................25

VITA 


\section{LIST OF TABLES}

Table 3-1. Permeation enhancers used in oral TPP formulation .................................8

Table 3-2. $\quad$ Strategies for improving oral bioavailability of TPPs ...............................19 


\section{LIST OF FIGURES}

Figure 2-1. Key contributors in G.I.T. governing oral delivery of TPPs ........................5 


\section{LIST OF ABBREVIATIONS}

TPPs

I.V.

I.P.

I.M.

G.I.T.

CPP

NDA

BLA
Therapeutic peptide and protein-based drugs

Intravenous

Intraperitoneal

Intramuscular

Gastrointestinal tract

Cell penetrating peptides

New drug application

Biological license application 


\section{CHAPTER 1. INTRODUCTION}

Peptide and proteins are most important part of the body which governs the functions of human body. In last few year, significant progress in the field of molecular biology and biochemistry have led to better understanding of these molecules role in different disease conditions starting from neurological disorders to cancer. Currently, small molecule drugs ( $<900$ dalton) have more prominent presence in the pharmaceutical market than the therapeutic peptide and protein-based drugs (TPP) dominate pharmaceutical drug market. However, the game is changing with the recent advances of biotechnological tools like recombinant DNA technology, solid phase protein synthesis etc. which enabled large-scale production of therapeutic peptide and proteins [1]. Success of Human Insulin, first FDA approved commercial recombinant protein based therapeutic in 1982 revolutionized the field of TPPs [2]. Over the next three decades, domain of TPPs have grown significantly in both academia and industry. In 2018, FDA's Center for Drug Evaluation and Research (CDER) approved 17 BLAs (biologics license application), which was highest in last two decades. Number of FDA approved TPPs reached to $\sim 239$ in 2017 where as it was only $\sim 130$ in 2008 [3, 4]. According to the report by Zion market research, global peptide based therapeutics market was estimated at approximately USD 23.06 billion in 2017 and anticipated to reach around USD 43.26 billion by 2024 [5]. The global oral proteins and peptides market is estimated around USD 643 million and likely to grow around $\$ 8,233$ million by 2028 [6].

Rapid progress in this sector can be attributed to proteins and peptides several advantages over small molecule drugs both financially and clinically. From a clinical perspective, proteins and peptides are inherently more specific to the target site than the small molecule drugs, which led to less interference with normal biological system of the patient and cause minimal off-target side effects. A handful of proteins which are used for different clinical complications are less immunogenic because they are produced in the body naturally. Furthermore, proteins and peptides also take part in several complex and complicated biological processes, which is difficult to be mimicked by the small molecule drugs. From a financial standpoint, median total pre-market development times were shorter for biologics (10.6 years) than the small molecule drugs (12.6 years) estimated using Merck Index. In 2009, US Congress passed the Biologics Price Competition and Innovation Act (BPCIA) which gave new biologics 12 years of guaranteed exclusivity [7]. Thus, the road to the commercial market is comparatively easier for the biologics in compared to the small molecule drugs.

The most commonly utilized routes for administering TPPs are I.V, I.P or I.M injections which largely suffers from patient compliances. There are $\sim 350$ TPPs under clinical development and among them only 2 are given orally e.g. Interferon- $\alpha$ and Human growth hormone. Currently most efforts in both the Pharmaceutical industry and academia are centered to enhance bioavailability of orally administered TPPs which typically less than $1 \%$ [8]. Oral administration is the most preferred route of drug administration for the patients. Advantages of oral administration also includes 
avoidance of pain and discomfort with injections. Furthermore, oral dosage forms are cheaper to manufacture as well as administer because they do not need to be produced under sterile conditions or administered in a clinic [9].However, unfavorable physicochemical characteristics of TPPs like high molecular weight, hydrophilicity, poor stability in the physiological conditions, short biological half-life, low permeability through the epithelial barrier in the small intestine put up a huge barrier for the development of orally available dosage forms of TPPs [10]. An ideal oral drug delivery platform for TPPs should retain its therapeutic activity and protect it from the proteolysis and heavily acidic environment of the stomach before releasing it in its active form in the neutral environment of the intestine to get absorbed in the blood stream. In this review, we will discuss the challenges associated with oral delivery of TPPs and ongoing efforts to solve them. 


\section{CHAPTER 2. CHALLENGES ASSOCIATED WITH ORAL DELIVERY OF PEPTIDES AND PROTEINS}

\section{Enzymatic Barriers of the Digestive System}

Orally administered TPPs and food face similar hurdles while passing from the mouth to the anus through G.I.T (esophagus, stomach, small intestine, and large intestine) before getting absorbed in the small intestine. That is why understanding of the anatomy and physiology of the different components of the G.I.T is crucial for successful design of oral dosage formulation of TPPs. Most of the nutrients are absorbed through the small intestine, while absorption in mouth, stomach is very minimum [11]. In mouth, saliva is mixed with the ingested food and helps in smooth movement to esophagus. Protein degradation in mouth and esophagus is minimal though mouth saliva contains amylase, lipase which helps in digestion of starch and fat respectively [12]. Acidic environment $(\mathrm{pH}$ 1.5-3.5) of the stomach is maintained by the gastric acid (hydrochloric acid, potassium chloride, and sodium chloride) which is secreted from oxyntic cells [13]. Acidic environment destabilizes protein and peptide structure and exposes peptide bonds for pepsin degradation. The major enzymatic degradation of the proteins and peptides occur in the small intestine which contains significant amount of proteases from the pancreas and cellular proteases from the mucosal cells [14].

Intestinal enzymes like pepsin, trypsin, chymotrypsin, elastase with the aid of acidic environment of stomach primarily facilitate protein and peptide breakdown and then convert them into smaller amino acid units $[15,16]$. Pepsinogen, in presence of the hydrochloric acid present in the gastric juice is converted to pepsin which is involved in breaking down the peptide bonds of amino acids (L-phenylalanine, L-tyrosine, Ltryptophan, and L-leucine) adjacent to a hydrophobic amino acid [17]. Thus, the gastrointestinal enzymes put up a huge challenge for oral delivery of TPPs. Encapsulation in sustained releasing nanoparticles or enteric coating is widely used to protect TPPs from the enzymatic degradation [18]. A no of factors such as a) molecular weight, b) hydrophilicity, c) Hydrogen bond donor/accepting potential, D) higher no of enzyme susceptible groups E) Low flexibility of the structure can be accountable for protein degradation in the G.I.T.

\section{Transport Across the Epithelial Membrane in The Small Intestine}

Epithelial barrier can possibly be crossed via three different mechanisms. They are paracellular transport, passive transcellular transport and active carrier mediated transcellular transport. Paracellular (transport of the molecules between the cells) or transcellular pathways (transport of the molecules into or across the cells) are most common by which molecules passively diffuse through the epithelial membrane. Most TPPs are highly hydrophilic in nature with a minute $\log P$ value $(<0)$ and expected to follow the paracellular pathways. Three different junctions are present in the intestinal epithelial lining: desmosomes or zonulae adherens, tight junctions or zonulae occludens, 
and gap junctions [19]. Tight junctions, present between neighboring epithelial cells puts up a significant challenge for the paracellular transportation of large molecules $(>100$ $200 \mathrm{Da}$ ) across the intestinal epithelium [20]. Typically molecules with a radius not larger than $11-15 \AA$ are reported to pass through the aqueous pores of tight junctions [21-23]. Absorption via paracellular pathway in small intestine found to be limited because small surface area estimated to be about $\sim 0.01 \%$ total area of the small intestine is available for absorption. Furthermore, charge on TPPs must also be taken into consideration along with size and hydrophilicity as the proteins that form the tight junction has polar amino acids and ionizable side chains which give it a negative net charge [24]. Increased concentrations of intracellular $\mathrm{Ca} 2+, \mathrm{cAMP}+$ decreases permeation of molecules at the tight junction [25].

Vaishali and co-workers have found paracellular pathway to be cation-selective where cations of weak bases showed a faster rate of permeation than the anions of weak acids [26]. Occludins, claudins and tricellulin are prime proteins at the tight junctions, which either governs several basic functions like formation of barrier, channels or specific tasks like signaling molecules, regulating absorption of certain molecules etc. [27]. In place of forming barriers, some proteins from the Caludin family such as claudin1 participates in barrier closing while Claudin-2, Claudin-10b and Cluaidin-10 forms cation and anion or cation selective channels respectively for paracellular transport [28, 29]. Transcellular transport is more predominant for the TPPs and relies on molecular structure, partition co-efficient and physicochemical properties of the molecule like size, lipophilicity, fraction of ionized and unionized species [30]. Most orally approved drugs are absorbed passively by the transcellular pathway because of the large surface area of the brush border membrane available for absorption, which 1000 times is larger than the paracellular surface area [31]. Furthermore, permeability studies in Caco-2 monolayers showed lipophilic and higher molecular weight compounds choose transcellular route over paracellular transport [32].

The transcellular pathway is different from the paracellular pathway for few reasons. Mainly, it can be mediated by either passive diffusion or specific amino acid, peptide transporter or endocytosis while paracellular transport takes place via passive diffusion only [33]. During transcellular transport, TPPs are first absorbed at the brush border apical membrane following a diffusion gradient and then they move through the enterocytes to the basolateral membrane where it gets absorbed by facilitated diffusion with the help of specific active carrier transport proteins[34]. Figure 2-1 lists all the barriers associated with oral delivery of TPPs in G.I.T. 


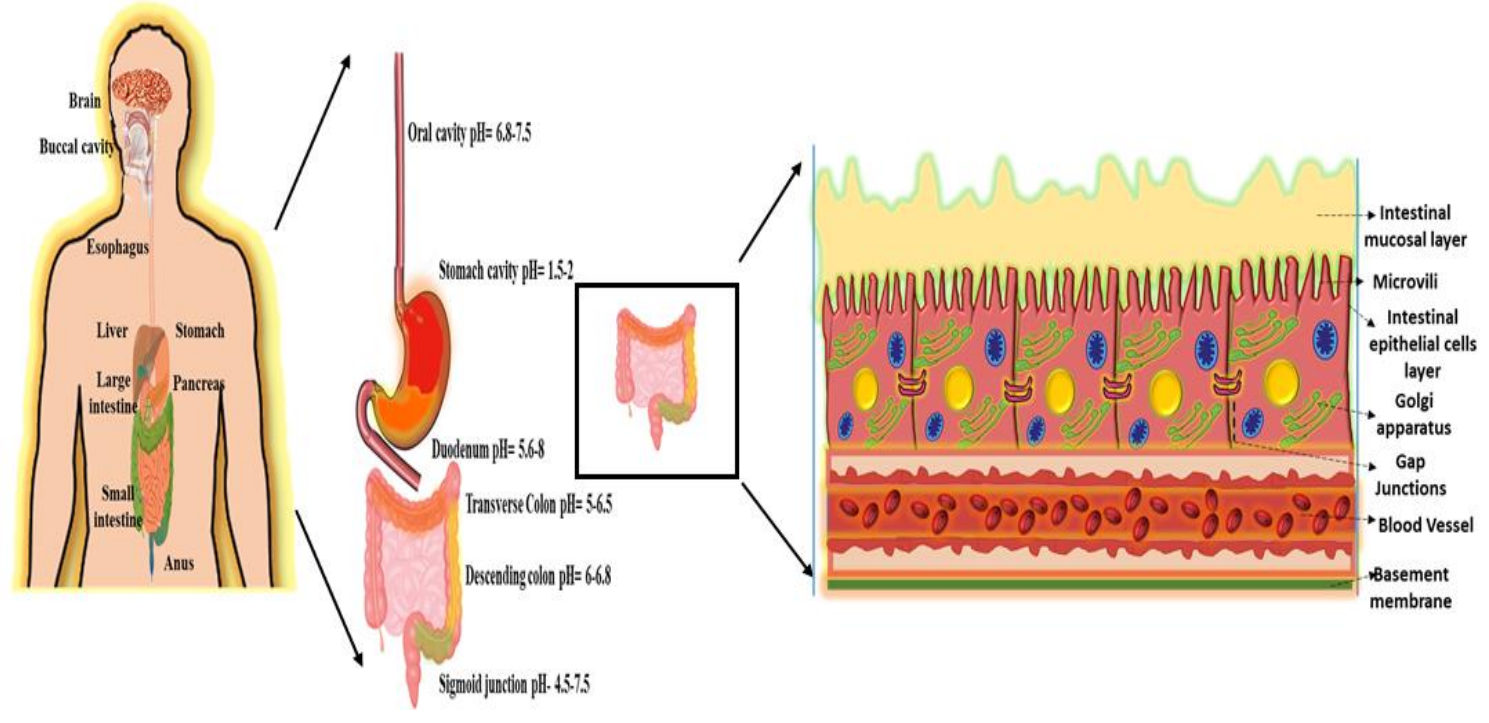

Figure 2-1. Key contributors in G.I.T. governing oral delivery of TPPs 


\section{CHAPTER 3. STRATEGIES FOR ENHANCING ORAL DELIVERY OF PROTEINS AND PEPTIDES}

\section{Permeation/Absorption Enhancers}

To show its therapeutic potency the orally administered TPPs must be absorbed in the systemic circulation. However, unfavorable physico-chemical properties result in low bioavailability of orally administered TPPs. Co-administration or incorporation of permeation enhancers improve bioavailability of TPPs by increasing their cellular permeability along the intestinal epithelia. Permeation enhancers modulate several functions, namely interacting with the membrane lipid or proteins and thus destroying cellular integrity of the tight junctions or opening it, lowering mucus viscosity and increasing in membrane fluidity etc. which provide a temporary route to cross intestinal epithelia and reach the systemic circulation either via transcellular or paracellular pathways [35]. Although, non-selective destruction of the intestinal lipid surface may allow the toxins, undesirable pathogens present in the GIT to get absorbed in the systemic circulation [36]. Ideally, the intestinal epithelium disruption should be reversible and temporary. Tetradecylmaltoside used as permeation enhancer and increased oral bioavailability of the enoxaparin by reducing transepithelial electrical resistance in vitro in $\mathrm{C} 2 \mathrm{BBel}$ cell extracts. Although transepithelial electrical resistance was restored after 60 minutes of exposure of cells to tetradecylmaltoside [37].

Several chemical classes of these compounds like chelating agents (EDTA, EGTA), surfactants (Sodium lauryl sulfate), bile salts (Salicylates, sodium glycocholate), fatty acids (Oleic acid, Linoleic acid, Caprylic acid) and theirs salts are widely used as permeation enhancers in preclinical development of several TPP formulations. Chelating agents forms complexes with $\mathrm{Ca}^{2+}$ ions present in tight junction and dismantles the structural organization of tight junctions, which subsequently aids in paracellular permeability of the TPPs. Sometimes calcium chelating agents can be toxic because calcium depletion can induce significant injury to the cell structure by distorting actin filaments, adherent junctions and cell adhesion molecules [19].

Surfactant monomers accumulate at the brush border membrane of the intestinal wall and cause acute damage to augment TPP permeation. Wei J. Xia and co-workers have found a maximum surface pressure of $25 \mathrm{dyne} / \mathrm{cm}$ or more is needed to damage the biological membrane [38]. A wide range of surfactants including anionic (sodium dodecyl sulfate and sodium dioctyl sulfosuccinate) and non-ionic (polysorbate 80 and polyoxyl 40) surfactants are used in preclinical development of the TPPs. Anionic surfactants are more effective than the non-ionic surfactants in increasing transepithelial permeability [39]. Mechanism of medium chain fatty acids as absorption enhancer is not well understood in vivo though it is believed that it downregulates tricellulin and claudin5 expression which is important to maintain tight junction integrity and solubilizes phospholipid bilayer temporarily and reversibly [40]. Sodium caprate, sodium salt of medium chain fatty acid capric acid is already a FDA approved food additive also investigated as a absorption enhancer for oral delivery of insulin [41] and a GLP-1 
peptide analog using Gastrointestinal Permeation Enhancing Technology (GIPET ${ }^{\mathrm{TM}}$, Merrion Pharmaceuticals, Dublin, Ireland) [42]. Orally administered dispersions of Insulin with saturated fatty acids e.g. lauric, palmitic and stearic acid as absorption. enhancer restored the blood glucose level from 105 to $75 \mathrm{mg} / \mathrm{dl}$ in rabbit [43]. $10 \mathrm{mM}$ of sodium caprate induces rapid and reversible opening of tight junctions for paracellular pathway for intestinal absorption drugs up to $10 \mathrm{kDa}$ molecular weight[29].

Zonula occludens toxins (ZOT), produced from the bacteria vibrio cholera reversibly increase paracellular absorption of orally administered insulin in rabbit intestine by 10 fold via enhancing the permeability through the tight junctions without toxicity issues [44]. ZOT is only acts through a specific intestinal receptor reversibly and inactive in microflora containing colon, which is susceptible to mucosal damage $[45,46]$. $\gamma \mathrm{G}$, biologically active fragment of ZOT enhances intestinal absorption of drugs susceptible to efflux transporters by interacting with PGP [47].

Bile salts are negative charged endogenous surfactant used as potent permeation enhancers. They act above or sub critical micellar concentration (CMC) and on both the hydrophobic and hydrophilic domain of the biological membrane. They anchor at the lipid bilayer of the membrane and form micelles near CMC which leads to elimination of the membrane lipid components [48]. Sodium deoxycholate, a commonly used bile salt as an absorption enhancer and increased paracellular absorption of hydrophilic model drugs and both transcellular and paracellular absorption of the hydrophobic drugs by reducing the transepithelial electrical resistance in Caco-2 cell monolayers [49]. Bile acid salts are also used to increase oral bioavailibity of salmon calcitonin and insulin oral formulation [50]. Sodium taurodeoxycholate, a secondary bile acid isolated from the intestinal primary bile acid successfully improve oral absorption of epidermal growth factor peptide both in vitro Caco-2 and in vivo xenograft model [51, 52].

Last few decades, a wide variety of absorption enhancers have been investigated, but most of them are toxic due for causing irreversible and significant damage to the gastrointestinal mucosa[53]. However, successful development of permeation enhancers depends on three prime factors i) onset of action, ii) degree of permeation enhancement and iii) toxicity [54]. See Table 3-1 for commonly used permeation enhancers and their mechanism of action.

\section{Enzyme Inhibitors}

Biological drugs must retain their structural integrity before getting absorbed into the systemic circulation to exert their activity. Most orally administered TPPs are vulnerable to various proteolytic enzymes while passing through the GIT mainly stomach and small intestine. However, co-administering protease inhibitors like pancreatic inhibitor, soybean trypsin inhibitor, camostat mesylate and aprotinin increase orally administered TPPs bioavailability by reducing presystemic enzymatic degradation by trypsin or $\alpha$-trypsin [74]. Protease inhibitors can be classified structurally as follows i) amino acid based and modified inhibitors ( $N$-acetylcysteine), ii) Peptides and modified 
Table 3-1. Permeation enhancers used in oral TPP formulation

\begin{tabular}{lll}
\hline \multicolumn{1}{c}{ Class } & \multicolumn{1}{c}{ Examples } & \multicolumn{1}{c}{ Mechanism of Action } \\
\hline $\begin{array}{l}\text { Chelating } \\
\text { agents }\end{array}$ & EDTA, EGTA & $\begin{array}{l}\text { Modulates and perturbs structural } \\
\text { integrity of tight junctions } \\
\text { Destabilizes both proteins and lipid }\end{array}$ \\
& $\begin{array}{l}\text { Sodium lauryl sulfate, } \\
\text { Polyoxyethylene ethers, } \\
\text { Tween }\end{array}$ & $\begin{array}{l}\text { Desent at membrane and increase } \\
\text { present } \\
\text { intercellular space for transportation } \\
\text { of molecules } \\
\text { Endogenous surfactant, acts above }\end{array}$ \\
& $\begin{array}{l}\text { Salicylates, Sodium } \\
\text { glycocholate, }\end{array}$ & $\begin{array}{l}\text { CMC to eliminate membrane lipid } \\
\text { components }\end{array}$ \\
fatty acids and & Oleic acid, Linoleic acid, \\
theirs salts & Caprylic acid & $\begin{array}{l}\text { Disintegrates the tight junctions and } \\
\text { solubilizes phospholipid bilayers }\end{array}$ \\
\hline
\end{tabular}


peptides as protease inhibitor (bacitracin, cyclic dodecapeptide), iii) Polypeptide protease inhibitors (aprotinin), iv) non-amino acid based protease inhibitor (disisopropyl fluorophosphates, phenylmethylsulfonyl fluoride) [55]. Appropriate choice of enzymatic inhibitor depends on the location of the target enzyme and cellular distribution. So, they are further divided based on their location such as i) inhibitors of luminally secreted proteases (aprotinin) and ii) Inhibitors of membrane bound proteases (amastatin, bestatin) [55]. Non-amino acid-based inhibitors like disisopropyl fluorophosphates, phenylmethylsulfonyl fluorides downregulate serine proteases. Although they also inhibit acetyl cholinesterase, which makes them toxic and unacceptable for pharmaceutical use [55]. FK-448 is low toxic, non-amino acid based inhibitor of chymotrypsin which helped in increasing intestinal absorption of insulin in rats and dogs [56].

Other types of protease inhibitors e.g. chymostatin, aprotinin, Bowman-Birk inhibitor and aprotinin showed to increase bioavailability of orally administered Insulin microsphere formulation by preventing degradation via digestive enzymes like pepsin, trypsin and $\alpha$-chymotrypsin [57]. High molecular weight of the polypetide protease inhibitors like aprotinin allowed them to be efficiently formulated in the sustained release oral dosage forms such as insulin loaded poly(vinyl alcohol)-gel spheres [58]. Aprotinin is one of the pioneering enzyme inhibitors used in several oral TPP formulations because of its inhibitory action on trypsin and chymotrypsin [59].

There are few models to evaluate protective effects of these inhibitors. One of such tests for luminally-secreted protease activity is to incubate the TPP delivery system with the protease inhibitor in gastric or intestinal fluid at $37^{\circ} \mathrm{C}$ and then estimating percentage of residual drug in the medium [60]. For in vivo protease inhibitory studies, insulin is used as a model drug as it is degraded by both luminal and brush border proteases $[57,61]$. Enzymatic inhibitors have significantly contributed to enhance bioavailability of orally administered TPPs. Although sometimes their acute and irreversible activity can lead to inactivation or over activation of certain enzyme-activity which can cause severe side effects like unstable digestion of nutrition, hypertrophy and hyperplasia of pancreas etc. [62].

\section{Structural Modifications}

The purpose of structural modifications of TPPs is to improve resistance to proteolytic degradation, immunogenicity, improve membrane penetration or stability. It can be done in two ways. The first approach is modification of the accessible side chain amino acid groups. Another method is targeting carbohydrate groups of glycoproteins [63]. Permeation of peptides were enhanced by conjugating lipophilic molecules like fatty acids to peptides to increase the hydrophobicity of peptides. For example, two palmitic acid derivatives of insulin monopalmitoyl- and dipalmitoyl-insulin were synthesized. These derivatives were more effective as indicated by hypoglycemic effects in rats and less immunogenic than the native insulin [64]. GIT stability and permeation across the intestine was notably increased by chemical modification of thyrotropinreleasing hormone with lauric acid at the N-terminal pyroglutamyl group. Lauric acid 
conjugated thyrotropin-releasing hormone was stable in intestinal mucosa and efficiently up taken by the brush mucosa where it was converted into its native form [65]. Another approach is introduction of protective groups that prevent enzymatic degradation. A derivative of insulin with introduction of $\alpha$-lipoic acid offered excellent protection against the proteolytic enzyme trypsin. Lipoic acid has a disulphide bridge which acts a natural antioxidant [66]. Similarly introduction of ethoxycarbonylmethionine groups for protecting glycine and lysine amino groups kept the insulin intact even after 5 cycles of degradation [67].

Desmopressin is the synthetic and modified form of naturally occurring antidiuretic hormone vasopressin with few structural modifications. N-terminal amino acid of desmopressin was deaminated and levo-arginine at the $8^{\text {th }}$ position of $\mathrm{C}$-terminal was replaced with dextro-arginine. These changes enhanced passive transport of the desmopressin when compared to vasopressin through the intestinal epithelia possibly because of protection from the proteolytic degradation [68]. Another method is cyclization, which increases half-life of the TPPS by protecting them from degradation by the exo and endopeptidases present in the blood. Typically, proteolytic enzymes favor flexible structures as their substrate. However cyclization rigidifies conformations of peptides and proteins which decreases the susceptibility of enzymatic degradation [69].

\section{PEGlyation}

Most of the TPPs suffer from their short biological life due to rapid clearance and inherent low stability due to proteolytic enzymes in systemic circulation. However, these shortcomings of the TPPs can be overcome by covalent binding of a biocompatible polymer to shield it from enzymatic degradation and improved properties like low immunogenicity, enhanced bioavailability and pharmacokinetic profile. A handful of polymers such as PHPMA, POEGMA, PNIPAM, PLGA, PDEAM, PEG used for oral delivery of TPPs. PEG has become the most widely studied among them due to several advantages like biocompatibility, less toxicity, improved biological and circulation halflife and low cost compared other polymers of the same molecular weight available [70]. PEG is amphipathic in nature soluble in both polar and non-polar solvents [71]. PEG can be derivatized with a functional group, which will allow chemical conjugation with reactive amino acids of protein or peptides. This process is known as PEGylation [72]. PEGylation protects the structural integrity of TPPs by shielding them from proteolytic enzymes before absorption. Thus, PEGylation increases the duration of action of TPPs in human body. Another important aspect of PEGylation is to decrease immunogenicity. PEG layer safeguards TPPs from the rapid and intense immune reaction when recognized by antibodies, B cells. $\alpha$-momorcharin $(\alpha-\mathrm{MMC})$, a type I ribosome-inactivating protein when PEGylated showed less immunogenicity and immunotoxicity in vivo [73]. Conjugation of PEG increases the size of small peptides so that they are less readily excreted by glomerular filtration [62]. Abuchowski and coworkers first reported of superior properties of BSA-PEG conjugates than the alone BSA [74]. Since then FDA has approved a handful of parental PEG-modified TPP formulations and several of them are investigated in clinical trial [75]. Their successfulness in oral delivery is reported 
though limited when compared to the parental dosage forms. Jensen-Pippo KE and coworkers reported recombinant human granulocyte colony stimulating factor-PEG complex effective orally by increasing stability and retention in vivo [76].

An insulin-PEG delivery system with a thoiolated polymer poly(acrylic acid)cysteine carrier matrix was more stable in vitro and effective in redcuing blood glucose levels in diabetic mice when administered orally than the native insulin [77]. Hexylinsulin monoconjugate or HIM2 is an orally delivered human insulin modified with a small PEG and permeation enhancer at the Lys- $\beta 29$ residue via an amide bond. Oral single administration of HIM2 $(0.75 \mathrm{mg} / \mathrm{kg})$ increased whole-body glucose disposal and inhibited endogenous glucose production in healthy nondiabetic human subjects in a dose dependent manner [78]. HIM2 was also found to be effective in type1 and 2 diabetic subjects $[79,80]$. NOBEX Corporation and BIOCON have jointly developed HIM2 and it is approved as Insugen in India [81].

\section{Mucoadhesive Polymeric Systems}

Mucoadhesive polymers such as hydroxyl propyl methyl cellulose, chitosan, carbopol provide an excellent platform for oral delivery of TPPs. The process of adhesion of these polymers to the mucosal tissue in GIT is known as muco-adhesion. Mucoadhesion enhances degree of drug absorption by extending the residence time of the drug carriers at the absorption site and providing higher drug concentration to absorption site. Hydrophilicity and high molecular weight of the mucoadhesive polymers help in enhancing solubility of poorly absorbed peptide and proteins while protecting them from enzymatic degradation in GIT [82]. A chitosan-coated nanosphere with elcatonin significantly enhanced the physiological effect that is reduction in blood calcium level when compared to the uncoated nanosphere and elcatonin solution in rat [83]. Ntrimethyl chitosan chloride, partially quaternized derivative of chitosan showed enhanced absorption than the normal chitosan salts in neutral and basic conditions [84]. Polymer properties dramatically change in respect to change in the environment $\mathrm{pH}$, temperature, ionic strength or presence of certain enzymes. For examples, PAA (poly acrylic acid) or PMA (poly methacrylic acid) hydrogels with azoaromatic crosslinkers are developed for colon-targeted delivery of macromolecules. Swelling of these polymers occurs only with an increase in $\mathrm{pH}$ and highest in neutral $\mathrm{pH}$ of colon. However, azoreductase, produced by the microbial flora of the colon can degrade azoaromatic linkers [85]. Another example of stimuli-sensitive mucoadhesive polymeric system is insulin loaded microparticles $(100-150 \mu \mathrm{M})$ constituted of PMA and polyethylene glycol (PEG) crosslinked P(MAA-g-EG)) polymer network. P(MAA-g-EG)) polymer network inhibits calcium dependent proteolytic enzymes such as trypsin [86].

Furthermore, insulin is protected in the acidic environment of the stomach as the polymer network only swells and releases the cargo in the neutral and basic environment of the intestine. PEG molecules provide adhesive properties for this formulation by penetrating into the mucosa [87]. Orally administered insulin loaded microparticles showed good pharmacokinetic properties and hypoglycemic effect both in healthly and 
diabetic rats and these effects last up to $8 \mathrm{hrs}$ following administration [87]. Incorporating a biocompatible endogenous permeation enhancer such as spermine, spermidine improved bioavailability of calcitonin-loaded mucoadhesive PAA nanoparticles. Spermine incorporated nanoparticles showed significant and prolonged reduction in blood calcium level when given orally in rats. This polyectrolyte nanoparticle complex were made from the interaction of the carboxylate groups of the PAA and magnesium ions or the amino acid groups of the spermine [88].

Another mention worthy mucoadhesive delivery system is GI-MAPS developed for oral administering of TPPs. GI-MAPS has four distinct layer serving different purposes contained in an enteric molecule. The backing layer is formulated with a waterinsoluble polymer ethyl cellulose which gives protection from proteolytic enzymes. Then comes the surface layer which is coated an adhesive layer and made up of an enteric $\mathrm{pH}$ sensitive polymer like hydroxypropylmethylcellulose phthalate (HP-55 $\left.{ }^{\circledR}\right)$, Eudragit $\mathrm{L} 100^{\circledR}$ or $\mathrm{S} 100^{\circledR}$. The middle portion containing the drug and pharmaceutical excipients like organic acid (citric acid), polyoxyethylated castor oil derivative (HCP-60 ${ }^{\circledR}$ ) is made of cellulose, which is conjugated to the ethyl cellulose by heating press method. The surface layer was connected to the middle layer by an adhesive carboxyvinyl polymer (Hiviswako ${ }^{\circledR} 103$ ). This unique system was studied to deliver a protein recombinant human granulocyte colony-stimulating factor (G-CSF) orally in beagle dogs and the pharmacological effect (increase in tota white blood cells count) was increased by 1.3 folds [89]. Thiolated mucoadhesive polymers have superior mucoadhesive properties than then conventional ones as thiol groups help in forming strong covalent disulfide bonds with the cysteine groups of mucous glycoproteins. Mucoadhesive properties of these polymers increase with the increase in thiol groups present. They also renders enzymatic protection [90]. Thiolated chitosan polymers exhibited 3 fold higher permeation rate when studied using passive diffusion marker rhodamine 123 compared to the unmodified chitosan [91].

High MW thiomers have better mucoadhesive characteristics due to significant entanglement with the mucus glycoproteins caused by long chain polymer but the suffer from deficient mobility and penetration across the mucus layer [92]. However, short chain low MW thiomers show higher penetration and mobility but negligible entanglements [93]. Combing both of the thiomers have resulted in better gelling and mucoadhesive properties [94]. Although mucoadhesive polymer showed improved absorption properties but their application is limited because of the mucus turnover process that takes place in every $12-24 \mathrm{~h}$ in the human intestine [95].

\section{Cell Penetrating Peptides}

Early research has showed the drawbacks and challenges related to the therapeutic activity of oral delivered TPPs. Hydrophilic nature of peptides and proteins makes it difficult to cross the lipophilic epithelial membranes, thus resulting in low bioavailability and absorption [96, 97]. For improving oral delivery of TPP based formulation, cellpenetrating peptides (CPP) are introduced. These CPPs are the protein transduction 
domain made up of 3-30 protein residues. The hydrophilic and hydrophobic parts of CPPs facilitate the internalization and conjugation of various entities such as liposomes, nanoparticles to the targeted sites [98]. The mode of membrane permeation by CPPs depends on the following factors such as sequence, the concentration of CPP, incubation volume and the reaction involved in the preparation of CPP attached to the protein cargo [99]. CPPs are used as vehicles for conjugating desired TPPs by covalent conjugation or physical complexation. Covalent conjugation between CPP vector and its cargo protein occurs due to disulfide bonds, amide bonds, or by using specific linkers [99, 100]. Physical complexation within vector CPP and cargo TPP source occurs by electrostatic or hydrophobic interaction, which is obtained by mixing vector and protein at a maintained CPP concentration $[101,102]$. Physical complexation can also occur between CPPs and hydrophilic protein using amphiphilic linkers. The most frequently used CPPs are primarily obtained from the transcriptional activator protein present in the HIV-1 virus.

CPPs are basically peptides with a high concentration of basic amino acids. The commonly used peptides are model amphipathic peptide (MAP), transportan, and antennapedia [103, 104]. CPPs may follow two paths for delivering TPPs at the targeted site. First, by direct penetration, which involves disturbance and distortion of lipid bilayer membrane leading to the availability of a molecule at the cytoplasmic site. Second, by endocytosis. These paths help in enhancing the permeability and bioavailability of proteins [105]. In natural conditions, it is impossible for the proteins to trigger therapeutic activity against different organelles or the cell nucleus by itself, due to reduced membrane permeability [106]. Hence, the functional groups present in CPPs facilitate the therapeutic protein within the cytoplasm to trigger such therapeutic activity. As proteins are one of the gold standards for nonimmunogenic therapy for treatments, CPPs play a prime role as a vector for enhancing protein delivery. Previous works by Dowdy and group showed that the use of the HIV-TAT CPP vector has successfully enhanced the uptake of high molecular weight protein beta-galactosidase $(120 \mathrm{kDa})$ across the bloodbrain barrier, which has been previously failed to be delivered majorly due to its large size and physiochemical property [107].

Being small sequence protein, CPPs with peptide bonds are vulnerable towards environmental changes that make their stability and use quite challenging and limited [108]. From the findings of Verdurmen and others on cationic CPPs of L and D amino acids, it is observed that the D form of amino acid showed a decreased uptake in MC57 fibrosarcoma and HeLa cells, which affects the overall uptake of CPP. Thus stereochemistry of the CPPs might be explored for efficient cellular targeting [109]. Changing amino acid stereochemistry or by modifying amino acid groups at specific sequences to avoid excess cleavage caused by proteases uptake of TPPs can be enhanced. In a CPP made up of human calcitonin, N-methyl-phenylalanine has substituted the Dphenylalanine group at a specified position of the protein, which has decreased the degradation of CPP without altering its penetration property when targeting HEK 293T cells [110]. 
Besides being vulnerable to proteolytic enzymes, the high molecular weight and low solubility of proteins make its delivery through the oral route difficult. Ganguly and group have done extensive work with naked (one which has no CPP attached group) 125I-labeled Polyamine Nucleic Acid TransActivation Response (PNATAR) and the CPP conjugates namely, 125I-labeled PNATAR-penetratin and 125I-labeled PNATARTAT. Studies on Balb/C mice showed a proper distribution and retention of the CPP conjugated radio-labeled protein within the organs. Radioactive labeled CPP conjugated protein showed rapid clearance from different organs, but a significant amount of the protein showed a controlled release for an extended period. Although the control 125Ilabeled PNATAR group showed similar distribution and clearance profile as that of the CPP conjugated PNATAR groups in Balb/C mice, its uptake was quite lower than the CPP conjugated groups [111]. Polyamine Nucleic Acids (PNAs) are the recently used DNA mimics used as a potent antiviral agent that lack the phosphate sugar backbone. The PNAs are protected against the catalytic degradation caused by proteolytic enzymes [112]. PNAs target and inhibit the Trans Activation Response (TAR) element of the viral genome. Combining CPPs such as penetratin and TAT with PNAs improves delivery of PNAs because CPPs enhance the affinity of the PNA complex for the TAT region of the virus [113].

\section{Enteric Coating for Oral Delivery of Peptides}

TPPs are absorbed in the small intestine where the $\mathrm{pH}$ is higher than stomach and pancreas. They are highly sensitive towards enzymatic degradation, which requires special protection from the gastric and pancreatic enzymes. For protecting TPPs from degradation, $\mathrm{pH}$ sensitive polymers are used as enteric coating. These polymers protect proteins from low stomach $\mathrm{pH}$ and accelerates its release at absorption site of small intestine. For example, oral delivery of insulin require such polymer to enable sitespecific release while passing down the GIT [36]. Currently the preferred way of delivering insulin is parenteral route of administration but, being a protein produced naturally by pancreas, it is susceptible towards degradation from proteolytic enzymes when it passes down the GIT [114]. For enhancing and controlling the $\mathrm{pH}$ specific oral delivery of insulin within the GIT, Touitou et al designed oral delivery platform for insulin. Gelatin capsules were used for encapsulating insulin where these capsules were enterically coated with different ratio of polyacrylic polymer (Eudragit RS, L and S) to facilitate $\mathrm{pH}$ dependent insulin release. In vivo studies in rat showed maximum insulin release at $\mathrm{pH} 7.5$ and 8 from the formulation containing Eudragit RS1 and RS2 respectively. Hypoglycemic studies by measuring blood glucose concentration of rats showed significant level of hypoglycemia obtained from both the formulation when compared to control group [115].

Another $\mathrm{pH}$ sensitive polymer which has been used for successful oral delivery of insulin is Methacrylic acid copolymer. This polymer can serve as a protection for insulin from enteric and pancreatic peptidases and also allow synthesis in a commercial scale [116]. Gwinup and co-workers utilized the previous work done by Schroender et al. and used of Methacrylic acid copolymer encapsulated 5-amino-salicylic acid formulation for 
treating ulcerative colitis. Methacrylic acid copolymers are soluble in $\mathrm{pH}$ above 7 and are itself non-toxic in nature $[117,118]$. $\mathrm{pH}$ sensitivity of methacrylic acid encapsulated insulin showed its partial release in the colon and complete dissolution of polymer in the duodenum. X ray studies on formulation showed intact drug profile within the capsule until it reaches cecum region. Advantage of oral administration of insulin was observed over its parenteral administration by noticing that blood glucose level didn't decrease immediately after oral administration thereby avoiding the occurrence of immediate dramatic hypoglycemia which is observed after insulin injection [119].

There are few disadvantages associated with enteric coating of TPPs. Enteric coating enhances the bioactivity of encapsulated TPPs but does not play any role in enhancing the process of absorption. To minimize these drawbacks, in addition to the protein component, protease inhibitors and membrane permeability enhancers can be added which can enhance the overall efficacy of enterically coated TPP formulations [120]. Different sites of intestine have different $\mathrm{pH}$, microspheres are designed respective to the $\mathrm{pH}$ requirement of TPPs to be released throughout the intestine. It has been previously reported that for the absorption of insulin, an optimal region of small intestine is required. Mid-jejunum region of the small intestine is the most preferred site for insulin absorption which protects it from gastric and pancreatic enzyme [121]. Small intestine has a variation of $\mathrm{pH}$ range which going for upper to lower part of it therefore, for achieving an effective release of insulin throughout the intestine, different ratio of Eudragit has been used in a formulation made by Morishita and his group. Formulation was made using Eudragit L100 (L) alone which make the formulation sensitive towards $\mathrm{pH}$ 6. This facilitates drug release in upper intestinal region. This enteric formulation was further modified with adding 1 part of Eudragit S100 and 1 part Eudragit L100 and it is soluble at $\mathrm{pH} 7$ and above. This modification enhanced $\mathrm{pH}$ specificity of formulation throughout small intestine [122].

\section{Liposomes}

Recent days lipid-based carrier systems are widely studied to deliver proteins orally and in different stages of clinical development. However, conventional liposomal systems have not met with mention worthy success because of their inefficiency to encapsulate hydrophilic peptides and proteins. They also suffer from instability in GIT and poor permeation through the mucosa to reach the epithelial layer. However, these instabilities can be countered significantly via surface modifying the liposome with musoadhesive polymer like chitosan and protease inhibitors like aprotinin or the Bowman Birk Inhibitor. When calcitonin was delivered using this unique mucoadhesive polymer chitosan and protease inhibitor approtinin conjugate in rats, the area above the blood calcium concentration-time curve was increased 15 fold compared to the calcitonin solution [123].

Another surface modified mucoadhesive polymer based on liposome formulation is carbopol-lectin liposome conjugate. Lection, isolated from the Triticum vulgaris is a non-toxic glycoprotein which binds to $N$-acetyl-D-glucosamine sugar present in the 
intestinal mucus membrane [124]. Calcitonin loaded carbopol-lectin liposome conjugates were conjugated covalently via carbodiimide method and had better pharmacokinetic properties and pharmacological effect in vivo in compared to carbopol-calcitonin liposomes [125]. Silica coating on the liposomes also helped in preventing proeteolytic degradation of the encapsulated drug and increase encapsulation efficiency [126]. Fusogenic liposomes are made by fusing Sendai virus envelop glycoprotein, which helps in internalizing into the cytoplasm, by membrane fusion. Fusogenic liposomes encapsulated insulins showed enhance insulin absorption exhibited by a rise in hypoglycemic effect with very little mucosal damage [127].

Liposomes can be also be surface modified for site specifically delivery. For example, Liposomes made of distearoylphosphatidylcholine, phosphatidylserine, and cholesterol were selectively more by the peyer patches of the lower ileum [128]. First generation liposomes also suffered from low circulation systemic half-life. However, modifying surface of liposomes with PEG increased their circulation lifetime by protecting from the opsonization and capture by RES [129]. Polymerosomes are modified forms of liposomes with hydrophilic and hydrophobic block polymer with PEG as their hydrophilic block [128]. Polymerosomes have more mechanical stability and hydrophilic interior to incorporate more hydrophilic peptides and proteins. Although reported that they suffer from poor encapsulation efficiency as low as 5\% [130]. Another interesting study was double liposomes, which had an inner core of smaller liposome of size around $100 \mathrm{~nm}$ within the larger liposome. Four different types of inner liposomes (neutral, cationic, VET and cationic-VET) were prepared by either Coatsome ${ }^{\circledR}$ or mechanochemical method. Then the double liposomes were prepared by a combination of mechanochemical and glass-beads method. The hypoglycemic effect of the double liposomes with cationic charged core was better in the diabetic rats when administered orally. This is due to ability of the double liposomes to protect its cargo from enzymatic degradation and ability of the positively charged inner liposome to enhance intestinal absorption. This study emphasized the role of surface charge of the particles in intestinal absorption [131].

Hybrid silica nanoparticle coated liposomes were synthesized to counter physical instabilities of liposomes like vesicle aggregation, fusion and creaming during manufacturing and storage. Silica layer provides a strong protection at the liquid liquid interface and also enhances in vivo absorption [126]. Achaeosomes, engineered liposomes made with membrane lipid isolated from Sulfolobus acidocaldarius are superior to the traditional liposomes in lowering blood glucose levels when administered orally with insulin incorporated. Archaeobacterial lipids provide protection from extreme $\mathrm{pH}$, oxidation, action of bile salts and lipase [132].

\section{Microspheres}

Polymeric microspheres of certain size range $(1-1000 \mu \mathrm{M})$ can be an excellent alternative option for controlled oral delivery of peptide and proteins. They can be prepared by various techniques such as spray drying, solvent evaporation, phase 
separation-coacervation [133]. Drug can be released from them following several ways like polymer degradation/erosion or diffusion [134]. Polymeric microspheres have widely used in several oral vaccine preparation. For instance, Vibrio cholerae whole cell oral microsphere vaccine was formulated based on PLGA by double emulsification method with a high encapsulation efficiency up to $95 \%$. Japanese encephalitis virus vaccine was also prepared by encapsulating in a biodegradable PLGA based microsphere made by $\mathrm{W} / \mathrm{O} / \mathrm{W}$ solvent evaporation method [135].

Another orally administered PLGA microsphere of lactoglobulin was prepared by $\mathrm{W} / \mathrm{O} / \mathrm{W}$ method to treat newborns prone to allergies to milk proteins. Tween 20 was added in this formulation, which increased protein encapsulation efficiency and superior controlled release [136]. However, proteins suffered from instabilities when encapsulated in PLGA microspheres by w/o/w method. Proteins are surface active, and they have tendencies to be adsorbed at the water/organic interface, which can lead to aggregation and unfolding of their structure. Although these issues can be regarded by $\mathrm{S} / \mathrm{O} / \mathrm{W}$ or $\mathrm{S} / \mathrm{O} / \mathrm{O}$ method of encapsulation. This is because proteins are stable and rigid in the organic phase. There unfolding or structural modification does not take place [137]. Insulin loaded microparticles were fabricated from blends of PEG with poly (L-lactide) (PLA) homopolymer and poly (DL-lactide co-glycolide) copolymers by water-in-oil solvent extraction method which showed a really high encapsulation efficiency up to $56 \%$ [138].

Biologically erodible microsphere formulation with polyanhydride copolymers of fumaric and sebacic acid, poly (FA:SA) demonstrated better adhesive properties than the microsphere made of other polymers. They can also penetrate through the intestinal epithelium as well as follicle-associated epithelium covering the lymphoid tissue of Peyer's patches [139]. $\mathrm{pH}$-sensitive microspheres were synthesized based on chemically modified soybean hydrolysate with aromatic acyl chlorides. These low-cost microspheres were stable $\mathrm{pH}<3.5$ and soluble at $\mathrm{pH}>5.0$. Oral delivery of salmon calcitonin or porcine insulin using these microspheres resulted into higher bioavailability [140]. Recently, using membrane emulsification technique combining $\mathrm{Ca} 2+$ ion and chitosan polymer solidification alginate-chitosan insulin microspheres were synthesized with excellent loading efficiency (56\%) and activity maintenance (99.4\%). These microspheres showed remarkable stability in stimulated gastric fluid and reduced blood glucose level successfully in diabetic rats for long time until $\sim 60 \mathrm{~h}[141]$.

\section{Microparticles/Nanoparticles}

Nanoparticles or microparticles of certain size ranges (10-200nm) are expected to penetrate through the mucus pores to reach the blood stream crossing the epithelial membrane. However, larger nanoparticles $(200 \mathrm{~nm}$ or $500 \mathrm{~nm})$ are also found to be effectively diffusing through the mucus layers if they are surface modified with PEG [142]. Nanoparticle absorption through GIT is governed by nature of its components, size and surface charge. Nanoparticle delivery systems have several advantages such as: i) protection from severe environment and proteolytic enzymes in GIT, ii) slow, controlled 
and site specific delivery of the cargo, iii) ability to cross the mucus membrane due to smaller size, iv) high volume and surface area for interaction with mucus and epithelial lining at GIT, v) allowing administration through non parenteral routes like oral route with improved bioavailability and pharmacokinetics properties etc. [105, 143-145]. A handful of polymers like alginate, chitosan, cyclodextrins, PLGA are used to manufacture nanoparticles for oral administering of TPPs.

Polymers can be further modified by grafting or substituting with functional groups that can used for targeting specific tissues or opening tight junction or mucoadhesion or permeation enhancing etc. [146]. In a recent study, alginate-chitosan nanoparticles were made by ionotropic pre-gelation method for oral delivery of insulin. This polyelectrolyte complexs were synthesized by coating alginate (anionic polysaccharide) containing insulin core with chitosan (cationic deacetylated form of chitin) by polyelectrolyte complexation method. FITC-insulin containing nanoparticles showed uptake on both the surface of the intestinal enterocytes and M-cells of the Peyer's patches. Also oral administration of these nanoparticles significantly reduced blood glucose levels in diabetic rats up to $59 \%$ and $55 \%$ when given dose of 50 and $100 \mathrm{IU} / \mathrm{kg}$ respectively [147].

Additionally, nanoparticles were engineered for site-specific uptake of the cargo by mononuclear phagocytic system to reduce off-target effects. It can be achieved by coating the surface of the by blood proteins for off opsonization. One of the disadvantages of this kind of delivery system is liver toxicity as most of the nanoparticle end up in liver for further purification. However, hydrophilic coating of the nanoparticles can reduce opsonization and uptake by mononuclear phagocytic system. [148].

Nanoparticle surface was also modified with ligands like $\mathrm{VB}_{12}$, lectins, biotins or folic acid to facilitate pronounced uptake by receptor mediated endocytosis [149]. See Table 3-2 for currently available strategies for improving oral bioavailability of TPPs 
Table 3-2. Strategies for improving oral bioavailability of TPPs

\begin{tabular}{|c|c|}
\hline Strategies & Results \\
\hline Permeation/Absorption & Increased permeability through the intestinal \\
\hline Enhancers & epithelia. \\
\hline Enzyme inhibitors & $\begin{array}{l}\text { Protection from acidic environment and proteolytic } \\
\text { enzymes in G.I.T. }\end{array}$ \\
\hline Structural modifications & $\begin{array}{l}\text { Increased permeability, solubility and resistance to } \\
\text { proteolytic degradation }\end{array}$ \\
\hline PEGlyation & $\begin{array}{l}\text { Protection from proteolytic enzymes, low } \\
\text { immunogenicity, enhanced bioavailability and } \\
\text { pharmacokinetic profile }\end{array}$ \\
\hline Cell penetrating peptides & $\begin{array}{l}\text { Enhanced permeation and site-specific delivery of the } \\
\text { TPPs }\end{array}$ \\
\hline $\begin{array}{l}\text { Mucoadhesive polymeric } \\
\text { systems }\end{array}$ & $\begin{array}{l}\text { Penetration through highly viscous mucus layer, } \\
\text { enzymatic protection, Site specific delivery }\end{array}$ \\
\hline $\begin{array}{l}\text { Microspheres, Nanoparticles } \\
\text { and Liposomes }\end{array}$ & $\begin{array}{l}\text { Improved bioavailability, pharmacokinetics, physical } \\
\text { stability, epithelial permeation and enzymatic } \\
\text { protection }\end{array}$ \\
\hline
\end{tabular}




\section{CHAPTER 4. CLINICAL INVESTIGATION OF ORAL PEPTIDES AND PROTEINS}

Oral delivery of TPPs is an excellent alternative to the current painful parenteral delivery. There is a continuous effort both in academia and industry to develop TPPs. However only few of them have got clinical approval. Here we have put few pivotal TPP formulation which are currently under different phases of clinical trials.

\section{Eligen ${ }^{\circledR}$ by Emisphere}

Eligen is a delivery agent which has been developed by Emisphere technologies. This company uses sodium N-[8-(2-hydroxy benzoyl) aminocaprylate] as a carrier molecule for attaching drug through weak non-covalent association. The integrity of drug remains unchanged when conjugated with the carrier molecule and can be delivered across the epithelial membrane. SNAC enhanced insulin absorption by 10 -fold transcellularly without damaging the tight jucntions significantly. It also helps in maintain GIT stability by protection from proteolytic enzymes. Oral insulin and regular insulin have been used with SNAC for treating type 2 Diabetes. It has completed its phase I trial (NCT00982254) [150]. Currently it is phase II clinical trial [151].

\section{CLEC by Altus Pharmaceuticals}

Crystallization of bulk protein is one of the methods to achieve purified proteins when required in bulk form. Produced protein crystals have stability much greater than its amorphous state therefore, this provides an additional advantage of crystallization. Protein crystallization generally involves the step of batch crystallization caused by crosslinking microcrystals with glutaraldehyde. These crosslinked enzyme crystals are known as CLEC are produced by Altus pharmaceuticals, which gives enzymes like polypeptides, lipases, esterase, and calcitonin enhanced stability. The produced products are stable against self and proteolytic digestion [152]. Commercially available TheraCLEC $^{\mathrm{TM}}$-protease along with TheraCLEC ${ }^{\mathrm{TM}}$-lipase are extensively used as pancreatic enzymes products and adjuvant therapy in autoimmune and infectious disease.

\section{BioOral by BioSante Pharmaceuticals}

Size and surface area of nanoparticles makes it a great vehicle for delivering proteins to site-specific areas. Nanoparticle act as one of the standard delivery vehicle because of its property of being nonimmunogenic, biodegradable, easy to modify, easy to metabolize ad stability during storage [153]. BioOral system has been developed as calcium phosphate-based nanoparticles for facilitating vaccine delivery known as BioSante. Oral delivery of insulin has been formulated as CAP-PEG-Insulin-Casein (CAPIC) where casein encapsulate the insulin-PEG formulation thereby act as an enteric 
coat to protect insulin from stomach $\mathrm{pH}$. It is available in the market from BioSante Pharmaceuticals. It can be used as Ornithine decarboxylase stimulant, Phosphokinase stimulants, and protein tyrosine kinase stimulant [154].

\section{Oral-Lyn $^{\mathrm{TM}}$ by Generex}

Oral- $\mathrm{Lyn}^{\mathrm{TM}}$ is another formulation used commercially for insulin delivery as aerosols. Generex biotechnologies have been developing this formulation using a minimum amount of excipient. Excipients used for formulating Oral-lyn are nonchlorofluorocarbon based propellent and stabilizing agents which protects the aerosolized protein formulation from denaturation. Insulin is converted into its micelle form with a size greater than $7 \mu \mathrm{m}$ which is too large to enter the lungs. RapidMist is a device profoundly used by people suffering from asthma, is also being used for delivering Oral-lyn directly into the oral cavity from which it penetrates down the buccal cavity and reaches the blood vessels. Clinical data shows that Oral-Lyn in its Phase III has been used for treating Diabetes Mellitus (NCT00668850) [81, 155]. Generex has been marketing the same product in India under the name of Oral Recosulin [156]

\section{HIM2 by Nobex and Biocon}

Hydrophilic proteins and peptides are difficult to deliver through oral route. Nobex and Biocon together are trying to address this limitation on a commercial scale by introducing lipophilic moiety into the protein structure. Hydrophobic nature of the protein would help in increasing its ability to cross the epithelial membrane. Companies have designed hexyl-insulin monoconjugate(HIM2), it is a modified form of insulin where amphiphilic oligomers conjugate with a primary amine group of the Lys-29 residue found in the beta chain of human insulin $[80,157]$. It is modified form of insulin, resistant to enzymatic degradation and improves insulin absorption when it is administered orally. Ongoing studies on HIM2 shows its use as a glucose stabilizer in type 1 Diabetes Mellitus [157].

\section{Oraldel $^{\mathrm{TM}}$ (ANL010) by Apollo Life Sciences}

Although enteric coating has shown successful delivery of insulin, proteolysis and absorption at intestinal enterocytes limit its commercial use [158]. To enhance the delivery of insulin, use of vitamin B12 has met with some success. Vitamin B12 when given in form of a dietary supplement, binds to the hepatocorrin salivary enzyme which stimulates the transport and absorption of vitamin B12 into the small intestine. Vitamin B12 binds further to the intrinsic factor and proceeds down to bind with the intrinsic factor receptor present in the wall of the ileum. These processes lead to the endocytosis of vitamin B12 and releasing it into the blood serum where it binds to transcobalamin (II). This conjugation of vitamin B12 eliminated major drawback associated with insulin delivery thereby causing internalization and transport of insulin in blood serum [159, 
160]. To enhance insulin delivery, Apollo life science has utilized the benefits of using Vitamin B12 for preparing sugar nanoparticle-based insulin coated with Vitamin B12 molecule. The formulation is termed as Oraldel ${ }^{\mathrm{TM}}$. In this formulation, insulin was encapsulated in the matrix of the nanoparticle. The company assures that this delivery system encapsulates $100 \%$ of the insulin in the matrix, therefore, can actively normalize blood glucose level, when delivered orally [98].

\section{AI-401 by Eli-Lilly and Autoimmune Inc.}

Use of recombinant technology is another approach for designing protein therapeutics which can be delivered orally. AI-401 is a recombinant insulin formulation which has been developed by Eli-Lilly. The company utilizes oral tolerance therapy for designing and developing AI-401. Oral tolerance therapy causes suppression of the immune response against an antigen [161]. Autoimmune Inc. together with Eli-lily has developed AI-401 to suppress the autoreactive T cells. Phase II clinical trial on this therapy has shown the normal working of endogenous insulin by delaying the destruction of Beta cells present in the pancreas. Clinical studies have successfully completed in patients suffering from Type I diabetes [162].

\section{Orasome by Endorex Corporation}

Liposomes are vehicles for delivery of therapeutics because of its resemblance to the cell membrane. They show excellent drug entrapment ability, biocompatibility, and safety. Liposomes are generally used for parenteral drug delivery because of its limitation towards oral delivery, caused generally because of its instability in the gastrointestinal tract and poor permeability for lipid membrane. Use of ligands and polymers have been attained to decrease the limitation associated with oral delivery using liposome [163]. Orasome, a polymer-based liposome has been designed by Endorex Corporation, which serves a purpose to protect insulin and human growth factor from the acidic stomach $\mathrm{pH}$ and releasing it into the small intestine. Orasome also helps in protecting the protein from low $\mathrm{pH}$ and bile salts [164].

\section{GIPET $^{\circledR}$ by Merrion Pharma and Novo Nordisk}

GIPET $^{\circledR}$ is another oral delivery technology used for enhancing protein absorption by as much as 200 times. This delivers oral therapeutics such as Insulin and GLP-1. GIPET is currently used in tablet form of insulin with three different coating and being studied for the treatment of Diabetes mellitus (NCT01931137) $[165,166]$. 


\section{Oramed by Oramed Pharmaceuticals}

Like GIPET, Oramed is also a carrier system used for delivering GLP-1 and Insulin. It is under phase II clinical trial when used for insulin delivery and phase I trial when used for GLP-I delivery. (NCT02535715) [167, 168]. Ormade's oral insulin is currently investigated for both type 1 and type 2 diabetes.

\section{Peptelligence $^{\mathrm{TM}}$ from Unigene Laboratories, Enteris Biopharma}

It is an enteric coated tablet formulation which increases solubility and absorptions of peptides. This formulation has two mail components. First a surfactant permeation enhancer which loosens the tight junctions and potentiates paracellular transport. It also works as excellent solubilizing agent. Another agent is a multifunctional $\mathrm{pH}$-lowering component citric acid, which increases absorptive flux. It furthers acts membrane wetting agent, calcium chelator. This strategy is under different stages for clinical compounds with different TPPs. TBRIA ${ }^{\mathrm{TM}}$, an oral calcitonin formulation for osteoporosis based on Peptelligence ${ }^{\mathrm{TM}}$ have completed phase 3 clinical trial and got NDA status from FDA $[169,170]$. 


\section{CHAPTER 5. CONCLUSIONS AND FUTURE DIRECTIONS}

Proteins and peptides play crucial roles in governing several biochemical processes in human body. Emil Behring started first use of antibody-based therapy back in early 1890. He with his friend Erich Wernicke were successful in developing a useful therapeutic serum against diphtheria. Then comes Frederick Banting who first used insulin as non-antibody-based therapy to treat diabetes in 1922. These initial successes were limited due to unavailability of large-scale peptide synthesis process as the early protein-peptides were isolated from animal sources.

The paradigm shift of TPPs from laboratory bench to industry happened after discovery of recombinant DNA technology and solid-phase protein synthesis which allowed large scale of synthesis of TPPs. A variety of peptides and proteins are currently in use for treating different diseases but mostly through the parenteral route. On the other hand, oral route is most preferred route for administration due to patient compliance and ease of administration. Therapeutic potential of TPPs is hampered by systemic instability in GIT and poor absorption through intestinal epithelia when administered orally. To exert its activity, TPPs must remain stable and active before reaching to the systemic circulation. In last few years, significant efforts were made for enhancing bioavailability orally administered peptides and proteins. A handful of absorption enhancers and enzyme inhibitors, structural modifications and carrier systems were developed tackle systemic instability and increase bioavailability of TPPs. These strategies have met with initial success but very few of them have made to the clinics. This certainly indicates the challenges in front of oral delivery of TPPs.

For achieving better result, it is necessary to understand the factors that affect GIT stability and permeation across the intestinal epithelia of TPPs. Current efforts are mostly directed to protect enzymes from acidic environment and proteolytic enzymes and enhancing their permeation. Most of the technologies, met with some success, have combined few strategies rather than using a single method. Though several studies have conducted on animals very few of them were done on human. Toxicity profile of formulation excipients in human should also be noted while developing a successful TPP formulation. Taking all these into consideration may lead to safer and successful development of orally administered TPP formulations. 


\section{LIST OF REFERENCES}

1. Merrifield, R.B., Solid Phase Peptide Synthesis. I. The Synthesis of a Tetrapeptide. Journal of the American Chemical Society, 1963. 85(14): p. 21492154.

2. Johnson, I., Human insulin from recombinant DNA technology. Science, 1983. 219(4585): p. 632-637.

3. Leader, B., Q.J. Baca, and D.E. Golan, Protein therapeutics: a summary and pharmacological classification. Nat Rev Drug Discov, 2008. 7(1): p. 21-39.

4. Usmani, S.S., et al., THPdb: Database of FDA-approved peptide and protein therapeutics. PLoS One, 2017. 12(7): p. e0181748.

5. Zion market research Global peptide based therapentics market report.

6. Oral Proteins and Peptides Market by Drug Type (Linaclotide, Plecanatide, Calcitonin, Insulin, and Octreotide) and Application (Gastric \& Digestive Disorders, Bone Diseases, Diabetes, and Hormonal Disorders): Global Opportunity Analysis and Industry Forecast, 2017-2028.

7. Beall, R.F., T.J. Hwang, and A.S. Kesselheim, Pre-market development times for biologic versus small-molecule drugs. Nature Biotechnology, 2019.

8. Lee VHL, D.-K.S., Grass GM et al. Oral route of peptide and protein drug delivery. In: Lee VHL (ed.). Peptide and protein drug delivery. New York: Marcel Dekker; 1991: 691-738.

9. Salama, N.N., N.D. Eddington, and A. Fasano, Tight junction modulation and its relationship to drug delivery. Advanced Drug Delivery Reviews, 2006. 58(1): p. 15-28.

10. Muheem, A., et al., A review on the strategies for oral delivery of proteins and peptides and their clinical perspectives. Saudi Pharmaceutical Journal, 2016. 24(4): p. 413-428.

11. Tortora GJ, G.S.P.o.A.a.P.t.e.N.Y.H.C., 1996.

12. Maton, A.H.B.a.H.P.H.I.-.-.--.

13. Marieb EN, H.K.H.a.p.S.F.B.C.I.----.

14. Woodley, J.F., Enzymatic barriers for GI peptide and protein delivery. Crit Rev Ther Drug Carrier Syst, 1994. 11(2-3): p. 61-95.

15. Kutchai HC. The gastrointestinal system. In: Berne RM, L.M., Koeppen BM, Stanton BA, editors. Physiology. 4th ed. St. Louis, MO: Mosby-Year Book; 1998. p. 587-674.

16. P.R. Kiela, F.K.G., Physiology of intestinal absorption and secretion, Best and P.R.C.G. 145-159.

17. Inouye, K. and J.S. Fruton, Studies on the Specificity of Pepsin*. Biochemistry, 1967. 6(6): p. 1765-1777.

18. Aguirre, T.A., et al., Current status of selected oral peptide technologies in advanced preclinical development and in clinical trials. Adv Drug Deliv Rev, 2016. 106(Pt B): p. 223-241.

19. Sood, A. and R. Panchagnula, Peroral Route: An Opportunity for Protein and Peptide Drug Delivery. Chemical Reviews, 2001. 101(11): p. 3275-3304. 
20. Turner, J.R., Intestinal mucosal barrier function in health and disease. Nat Rev Immunol, 2009. 9(11): p. 799-809.

21. Cereijido, M., I. Meza, and A. Martinez-Palomo, Occluding junctions in cultured epithelial monolayers. American Journal of Physiology-Cell Physiology, 1981. 240(3): p. C96-C102.

22. Madara, J.L. and K. Dharmsathaphorn, Occluding junction structure-function relationships in a cultured epithelial monolayer. The Journal of cell biology, 1985. 101(6): p. 2124-2133.

23. Rubas, W., et al., Flux measurements across Caco-2 monolayers may predict transport in human large intestinal tissue. J Pharm Sci, 1996. 85(2): p. 165-9.

24. Pauletti, G.M., et al., Structural requirements for intestinal absorption of peptide drugs. Journal of Controlled Release, 1996. 41(1): p. 3-17.

25. Soergel, K.H., Showdown at the tight junction. Gastroenterology, 1993. 105(4): p. 1247-1250.

26. Pade, V. and S. Stavchansky, Estimation of the Relative Contribution of the Transcellular and Paracellular Pathway to the Transport of Passively Absorbed Drugs in the Caco-2 Cell Culture Model. Pharmaceutical Research, 1997. 14(9): p. 1210-1215.

27. Schulzke, J.D. and M. Fromm, Tight junctions: molecular structure meets function. Ann N Y Acad Sci, 2009. 1165: p. 1-6.

28. Glahn, R.P., et al., Caco-2 cell ferritin formation predicts nonradiolabeled food iron availability in an in vitro digestion/Caco-2 cell culture model. J Nutr, 1998. 128(9): p. 1555-61.

29. Krug, S.M., et al., Sodium caprate as an enhancer of macromolecule permeation across tricellular tight junctions of intestinal cells. Biomaterials, 2013. 34(1): p. 275-282.

30. Lipka, E., J. Crison, and G.L. Amidon, Transmembrane transport of peptide type compounds: Prospects for oral delivery. Journal of Controlled Release, 1996. 39(2): p. 121-129.

31. Pappenheimer, J.R. and K.Z. Reiss, Contribution of solvent drag through intercellular junctions to absorption of nutrients by the small intestine of the rat. $\mathrm{J}$ Membr Biol, 1987. 100(2): p. 123-36.

32. Camenisch, G., et al., Estimation of permeability by passive diffusion through Caco-2 cell monolayers using the drugs' lipophilicity and molecular weight. Eur J Pharm Sci, 1998. 6(4): p. 317-24.

33. Fanning, A.S., L.L. Mitic, and J.M. Anderson, Transmembrane proteins in the tight junction barrier. J Am Soc Nephrol, 1999. 10(6): p. 1337-45.

34. Segura-Campos, M., et al., Bioavailability of Bioactive Peptides. Food Reviews International, 2011. 27(3): p. 213-226.

35. Choonara, B.F., et al., A review of advanced oral drug delivery technologies facilitating the protection and absorption of protein and peptide molecules. Biotechnology Advances, 2014. 32(7): p. 1269-1282.

36. Carino, G.P. and E. Mathiowitz, Oral insulin delivery. Adv Drug Deliv Rev, 1999. 35(2-3): p. 249-257. 
37. Yang, T., J.J. Arnold, and F. Ahsan, Tetradecylmaltoside (TDM) enhances in vitro and in vivo intestinal absorption of enoxaparin, a low molecular weight heparin. J Drug Target, 2005. 13(1): p. 29-38.

38. Xia, W.J. and H. Onyuksel, Mechanistic Studies on Surfactant-Induced Membrane Permeability Enhancement. Pharmaceutical Research, 2000. 17(5): p. 612-618.

39. Anderberg, E.K., C. Nyström, and P. Artursson, Epithelial Transport of Drugs in Cell Culture. VII: Effects of Pharmaceutical Surfactant Excipients and Bile Acids on Transepithelial Permeability in Monolayers of Human Intestinal Epithelial (Caco-2) Cells. Journal of Pharmaceutical Sciences, 1992. 81(9): p. 879-887.

40. Richard, J., Challenges in oral peptide delivery: lessons learnt from the clinic and future prospects. Therapeutic Delivery, 2017. 8(8): p. 663-684.

41. Morishita, M., et al., Site-Dependent Effect of Aprotinin, Sodium Caprate, $N a<S U B>2</ S U B>E D T A$ and Sodium Glycocholate on Intestinal Absorption of Insulin. Biological \& Pharmaceutical Bulletin, 1993. 16(1): p. 68-72.

42. Richard, J., Challenges in oral peptide delivery: lessons learnt from the clinic and future prospects. Ther Deliv, 2017. 8(8): p. 663-684.

43. Mesiha, M., F. Plakogiannis, and S. Vejosoth, Enhanced oral absorption of insulin from desolvated fatty acid-sodium glycocholate emulsions. International Journal of Pharmaceutics, 1994. 111(3): p. 213-216.

44. Fasano, A. and S. Uzzau, Modulation of intestinal tight junctions by Zonula occludens toxin permits enteral administration of insulin and other macromolecules in an animal model. J Clin Invest, 1997. 99(6): p. 1158-64.

45. Fasano, A. and S. Uzzau, Modulation of intestinal tight junctions by Zonula occludens toxin permits enteral administration of insulin and other macromolecules in an animal model. The Journal of Clinical Investigation, 1997. 99(6): p. 1158-1164.

46. Fasano, A., et al., The enterotoxic effect of zonula occludens toxin on rabbit small intestine involves the paracellular pathway. Gastroenterology, 1997. 112(3): $\mathrm{p}$. 839-846.

47. Salama, N.N., et al., The impact of DeltaG on the oral bioavailability of low bioavailable therapeutic agents. J Pharmacol Exp Ther, 2005. 312(1): p. 199-205.

48. Yang, L., I.G. Tucker, and J. Østergaard, Effects of bile salts on propranolol distribution into liposomes studied by capillary electrophoresis. Journal of Pharmaceutical and Biomedical Analysis, 2011. 56(3): p. 553-559.

49. Sakai, M., et al., Effects of absorption enhancers on the transport of model compounds in Caco-2 cell monolayers: assessment by confocal laser scanning microscopy. J Pharm Sci, 1997. 86(7): p. 779-85.

50. Song, K.-H., S.-J. Chung, and C.-K. Shim, Enhanced intestinal absorption of salmon calcitonin $(s C T)$ from proliposomes containing bile salts. Journal of Controlled Release, 2005. 106(3): p. 298-308.

51. Gaowa, A., et al., Bile Acid as an Effective Absorption Enhancer for Oral Delivery of Epidermal Growth Factor Receptor-Targeted Hybrid Peptide. Journal of Pharmaceutical Sciences, 2018. 107(5): p. 1322-1329.

52. Niu, M., et al., Hypoglycemic activity and oral bioavailability of insulin-loaded liposomes containing bile salts in rats: The effect of cholate type, particle size and 
administered dose. European Journal of Pharmaceutics and Biopharmaceutics, 2012. 81(2): p. 265-272.

53. Fasano, A., Innovative strategies for the oral delivery of drugs and peptides. Trends in Biotechnology, 1998. 16(4): p. 152-157.

54. Maher, S., R.J. Mrsny, and D.J. Brayden, Intestinal permeation enhancers for oral peptide delivery. Advanced Drug Delivery Reviews, 2016. 106: p. 277-319.

55. Bernkop-Schnurch, A., The use of inhibitory agents to overcome the enzymatic barrier to perorally administered therapeutic peptides and proteins. J Control Release, 1998. 52(1-2): p. 1-16.

56. Fujii, S., et al., Promoting effect of the new chymotrypsin inhibitor FK-448 on the intestinal absorption of insulin in rats and dogs. Journal of Pharmacy and Pharmacology, 1985. 37(8): p. 545-549.

57. Morishita, M., et al., Novel oral microspheres of insulin with protease inhibitor protecting from enzymatic degradation. International Journal of Pharmaceutics, 1992. 78(1): p. 1-7.

58. Kimura, T., et al., Oral administration of insulin as poly(vinyl alcohol)-gel spheres in diabetic rats. Biol Pharm Bull, 1996. 19(6): p. 897-900.

59. Yamamoto, A., et al., Effects of various protease inhibitors on the intestinal absorption and degradation of insulin in rats. Pharm Res, 1994. 11(10): p. 1496500 .

60. Bernkop-Schnürch, A. and K. Dundalek, Novel bioadhesive drug delivery system protecting (poly)peptides from gastric enzymatic degradation. International Journal of Pharmaceutics, 1996. 138(1): p. 75-83.

61. Ikesue, K., P. Kopečkovà, and J. Kopeček, Degradation of proteins by guinea pig intestinal enzymes. International Journal of Pharmaceutics, 1993. 95(1): p. 171179.

62. Kumar, T.R., K. Soppimath, and S.K. Nachaegari, Novel delivery technologies for protein and peptide therapeutics. Curr Pharm Biotechnol, 2006. 7(4): p. 261-76.

63. Mahato, R., et al., Emerging Trends in Oral Delivery of Peptide and Protein Drugs. Vol. 20. 2003. 153-214.

64. Hashimoto, M., et al., Synthesis of palmitoyl derivatives of insulin and their biological activities. Pharm Res, 1989. 6(2): p. 171-6.

65. Tanaka, K., et al., Enhancement of intestinal transport of thyrotropin-releasing hormone via a carrier-mediated transport system by chemical modification with lauric acid. Biochim Biophys Acta, 1996. 1283(1): p. 119-26.

66. Tao, H. and H. Kaixun, Synthesis, Characterization and Biological Activity of Chemically Modified Insulin Derivative with Alpha Lipoic Acid. Protein \& Peptide Letters, 2006. 13(2): p. 135-142.

67. Saunders, D.J. and R. Offord, Semisynthetic analogues of insulin. The use of $<e m>N</ e m>-$ substituted derivatives of methionine as acid-stable protecting groups. Biochemical Journal, 1977. 165(3): p. 479-486.

68. VILHARDT, H. and S. LUNDIN, In vitro intestinal transport of vasopressin and its analogues. Acta Physiologica Scandinavica, 1986. 126(4): p. 601-607.

69. Räder, A.F.B., et al., Improving oral bioavailability of cyclic peptides by $N$ methylation. Bioorganic \& Medicinal Chemistry, 2018. 26(10): p. 2766-2773. 
70. Pfister, D. and M. Morbidelli, Process for protein PEGylation. Journal of Controlled Release, 2014. 180: p. 134-149.

71. Greenwald, R.B., et al., Effective drug delivery by PEGylated drug conjugates. Adv Drug Deliv Rev, 2003. 55(2): p. 217-50.

72. Roberts, M.J., M.D. Bentley, and J.M. Harris, Chemistry for peptide and protein PEGylation. Adv Drug Deliv Rev, 2002. 54(4): p. 459-76.

73. Zheng, J.C., et al., PEGylation is effective in reducing immunogenicity, immunotoxicity, and hepatotoxicity of alpha-momorcharin in vivo. Immunopharmacol Immunotoxicol, 2012. 34(5): p. 866-73.

74. Abuchowski, A., et al., Alteration of immunological properties of bovine serum albumin by covalent attachment of polyethylene glycol. J Biol Chem, 1977. 252(11): p. 3578-81.

75. Alconcel, S.N.S., A.S. Baas, and H.D. Maynard, FDA-approved poly(ethylene glycol)-protein conjugate drugs. Polymer Chemistry, 2011. 2(7): p. 1442-1448.

76. Jensen-Pippo, K.E., et al., Enteral bioavailability of human granulocyte colony stimulating factor conjugated with poly(ethylene glycol). Pharm Res, 1996. 13(1): p. 102-7.

77. Calceti, P., et al., Development and in vivo evaluation of an oral insulin-PEG delivery system. Eur J Pharm Sci, 2004. 22(4): p. 315-23.

78. Wajcberg, E., et al., Dose-Response Effect of a Single Administration of Oral Hexyl-Insulin Monoconjugate 2 in Healthy Nondiabetic Subjects. Diabetes Care, 2004. 27(12): p. 2868-2873.

79. Clement, S., et al., Oral insulin product hexyl-insulin monoconjugate 2 (HIM2) in type 1 diabetes mellitus: the glucose stabilization effects of HIM2. Diabetes Technol Ther, 2002. 4(4): p. 459-66.

80. Kipnes, M., et al., Control of postprandial plasma glucose by an oral insulin product (HIM2) in patients with type 2 diabetes. Diabetes Care, 2003. 26(2): p. 421-6.

81. Park, K., I.C. Kwon, and K. Park, Oral protein delivery: Current status and future prospect. Reactive and Functional Polymers, 2011. 71(3): p. 280-287.

82. Takeuchi, H., H. Yamamoto, and Y. Kawashima, Mucoadhesive nanoparticulate systems for peptide drug delivery. Adv Drug Deliv Rev, 2001. 47(1): p. 39-54.

83. Kawashima, Y., et al., Mucoadhesive DL-lactide/glycolide copolymer nanospheres coated with chitosan to improve oral delivery of elcatonin. Pharm Dev Technol, 2000. 5(1): p. 77-85.

84. Kotzé, A.F., et al., Enhancement of paracellular drug transport with highly quaternized $N$-trimethyl chitosan chloride in neutral environments: In vitro evaluation in intestinal epithelial cells (Caco-2). Journal of Pharmaceutical Sciences, 1999. 88(2): p. 253-257.

85. Ghandehari, H., P. Kopečková, and J. Kopecek, In vitro degradation of pHsensitive hydrogels containing aromatic azo bonds. Biomaterials, 1997. 18(12): p. 861-872.

86. Madsen, F. and N.A. Peppas, Complexation graft copolymer networks: swelling properties, calcium binding and proteolytic enzyme inhibition. Biomaterials, 1999. 20(18): p. 1701-8. 
87. Lowman, A.M., et al., Oral delivery of insulin using pH-responsive complexation gels. Journal of Pharmaceutical Sciences, 1999. 88(9): p. 933-937.

88. Makhlof, A., et al., A mucoadhesive nanoparticulate system for the simultaneous delivery of macromolecules and permeation enhancers to the intestinal mucosa. Journal of Controlled Release, 2011. 149(1): p. 81-88.

89. Eiamtrakarn, S., et al., Gastrointestinal mucoadhesive patch system (GI-MAPS) for oral administration of G-CSF, a model protein. Biomaterials, 2002. 23(1): p. 145-152.

90. Leitner, V.M., M.K. Marschutz, and A. Bernkop-Schnurch, Mucoadhesive and cohesive properties of poly(acrylic acid)-cysteine conjugates with regard to their molecular mass. Eur J Pharm Sci, 2003. 18(1): p. 89-96.

91. Bernkop-Schnürch, A., D. Guggi, and Y. Pinter, Thiolated chitosans: development and in vitro evaluation of a mucoadhesive, permeation enhancing oral drug delivery system. Journal of Controlled Release, 2004. 94(1): p. 177-186.

92. Roldo, M., et al., Mucoadhesive thiolated chitosans as platforms for oral controlled drug delivery: synthesis and in vitro evaluation. Eur J Pharm Biopharm, 2004. 57(1): p. 115-21.

93. Albarkah, Y.A., R.J. Green, and V.V. Khutoryanskiy, Probing the Mucoadhesive Interactions Between Porcine Gastric Mucin and Some Water-Soluble Polymers. Macromolecular Bioscience, 2015. 15(11): p. 1546-1553.

94. Lam, H.T., et al., Thiomers: Impact of in situ cross-linkers on mucoadhesive properties. European Journal of Pharmaceutical Sciences, 2017. 106: p. 41-48.

95. Bernkop-Schnurch, A., et al., Thiomers: potential excipients for non-invasive peptide delivery systems. Eur J Pharm Biopharm, 2004. 58(2): p. 253-63.

96. Guidotti, G., L. Brambilla, and D. Rossi, Cell-Penetrating Peptides: From Basic Research to Clinics. Trends Pharmacol Sci, 2017. 38(4): p. 406-424.

97. Zorko, M. and U. Langel, Cell-penetrating peptides: mechanism and kinetics of cargo delivery. Adv Drug Deliv Rev, 2005. 57(4): p. 529-45.

98. Muheem, A., et al., A review on the strategies for oral delivery of proteins and peptides and their clinical perspectives. Saudi pharmaceutical journal : SPJ : the official publication of the Saudi Pharmaceutical Society, 2016. 24(4): p. 413-428.

99. Kristensen, M., D. Birch, and H. Morck Nielsen, Applications and Challenges for Use of Cell-Penetrating Peptides as Delivery Vectors for Peptide and Protein Cargos. Int J Mol Sci, 2016. 17(2).

100. Herce, H.D., et al., Visualization and targeted disruption of protein interactions in living cells. Nature Communications, 2013. 4: p. 2660.

101. Kamide, K., et al., Isolation of novel cell-penetrating peptides from a random peptide library using in vitro virus and their modifications. Int J Mol Med, 2010. 25(1): p. 41-51.

102. Virès, E., et al., Structure-activity relationship study of the plasma membrane translocating potential of a short peptide from HIV-1 Tat protein. Letters in Peptide Science, 1997. 4(4): p. 429-436.

103. Munyendo, W.L., et al., Cell penetrating peptides in the delivery of biopharmaceuticals. Biomolecules, 2012. 2(2): p. 187-202.

104. Torchilin, V.P., Cell penetrating peptide-modified pharmaceutical nanocarriers for intracellular drug and gene delivery. Biopolymers, 2008. 90(5): p. 604-10. 
105. Morishita, M. and N.A. Peppas, Is the oral route possible for peptide and protein drug delivery? Drug Discov Today, 2006. 11(19-20): p. 905-10.

106. Glover, D.J., H.J. Lipps, and D.A. Jans, Towards safe, non-viral therapeutic gene expression in humans. Nat Rev Genet, 2005. 6(4): p. 299-310.

107. Schwarze, S.R., et al., In vivo protein transduction: delivery of a biologically active protein into the mouse. Science, 1999. 285(5433): p. 1569-72.

108. Palm, C., et al., Peptide degradation is a critical determinant for cell-penetrating peptide uptake. Biochim Biophys Acta, 2007. 1768(7): p. 1769-76.

109. Verdurmen, W.P., et al., Preferential uptake of L-versus D-amino acid cellpenetrating peptides in a cell type-dependent manner. Chem Biol, 2011. 18(8): p. 1000-10.

110. Rennert, R., et al., Developing novel hCT derived cell-penetrating peptides with improved metabolic stability. Biochim Biophys Acta, 2006. 1758(3): p. 347-54.

111. Ganguly, S., et al., Pharmacokinetic analysis of polyamide nucleic-acid-cell penetrating peptide conjugates targeted against HIV-1 transactivation response element. Oligonucleotides, 2008. 18(3): p. 277-286.

112. Upadhyay, A., N.M. Ponzio, and V.N. Pandey, Immunological response to peptide nucleic acid and its peptide conjugate targeted to transactivation response (TAR) region of HIV-1 RNA genome. Oligonucleotides, 2008. 18(4): p. 329-335.

113. Kaushik, N., et al., Anti-TAR polyamide nucleotide analog conjugated with a membrane-permeating peptide inhibits human immunodeficiency virus type 1 production. J Virol, 2002. 76(8): p. 3881-91.

114. Nishihata, T., et al., Enhanced rectal absortion of insulin and heparin in rats in the presence of non-surfactant adjuvants. J Pharm Pharmacol, 1981. 33(5): p. 334-5.

115. Touitou, E. and A. Rubinstein, Targeted enteral delivery of insulin to rats. International Journal of Pharmaceutics, 1986. 30(2): p. 95-99.

116. Stolar, M.W., Atherosclerosis in diabetes: the role of hyperinsulinemia. Metabolism, 1988. 37(2 Suppl 1): p. 1-9.

117. Dew, M.J., et al., Colonic release of 5-amino salicylic acid from an oral preparation in active ulcerative colitis. British journal of clinical pharmacology, 1983. 16(2): p. 185-187.

118. Schroeder, K.W., W.J. Tremaine, and D.M. Ilstrup, Coated oral 5-aminosalicylic acid therapy for mildly to moderately active ulcerative colitis. A randomized study. N Engl J Med, 1987. 317(26): p. 1625-9.

119. Gwinup, G., A.N. Elias, and E.S. Domurat, Insulin and C-peptide levels following oral administration of insulin in intestinal-enzyme protected capsules. General Pharmacology: The Vascular System, 1991. 22(2): p. 243-246.

120. Wagner, A.M., M.P. Gran, and N.A. Peppas, Designing the new generation of intelligent biocompatible carriers for protein and peptide delivery. Acta pharmaceutica Sinica. B, 2018. 8(2): p. 147-164.

121. Agarwal, V., et al., Transport studies of insulin across rat jejunum in the presence of chicken and duck ovomucoids. J Pharm Pharmacol, 2001. 53(8): p. 1131-8. 
122. Morishita, I., et al., Enteral insulin delivery by microspheres in 3 different formulations using Eudragit L100 and S100. International Journal of Pharmaceutics, 1993. 91(1): p. 29-37.

123. Werle, M. and H. Takeuchi, Chitosan-aprotinin coated liposomes for oral peptide delivery: Development, characterisation and in vivo evaluation. International Journal of Pharmaceutics, 2009. 370(1): p. 26-32.

124. Nagata, Y. and M.M. Burger, Wheat germ agglutinin. Molecular characteristics and specificity for sugar binding. J Biol Chem, 1974. 249(10): p. 3116-22.

125. Werle, M., A. Makhlof, and H. Takeuchi, Carbopol-lectin conjugate coated liposomes for oral peptide delivery. Chem Pharm Bull (Tokyo), 2010. 58(3): p. 432-4.

126. Mohanraj, V.J., T.J. Barnes, and C.A. Prestidge, Silica nanoparticle coated liposomes: A new type of hybrid nanocapsule for proteins. International Journal of Pharmaceutics, 2010. 392(1): p. 285-293.

127. Goto, T., et al., Novel mucosal insulin delivery systems based on fusogenic liposomes. Pharmaceutical research, 2006. 23(2): p. 384-391.

128. Aramaki, Y., et al., Stability of liposomes in vitro and their uptake by rat Peyer's patches following oral administration. Pharm Res, 1993. 10(8): p. 1228-31.

129. Ducat, E., et al., Nuclear delivery of a therapeutic peptide by long circulating pHsensitive liposomes: Benefits over classical vesicles. International Journal of Pharmaceutics, 2011. 420(2): p. 319-332.

130. Arifin, D.R. and A.F. Palmer, Polymersome encapsulated hemoglobin: a novel type of oxygen carrier. Biomacromolecules, 2005. 6(4): p. 2172-81.

131. Yamabe, K., et al., Potentiality of double liposomes containing salmon calcitonin as an oral dosage form. Journal of Controlled Release, 2003. 89(3): p. 429-436.

132. Li, Z., et al., Investigation of archaeosomes as carriers for oral delivery of peptides. Biochemical and Biophysical Research Communications, 2010. 394(2): p. 412-417.

133. Patel, A., et al., Recent advances in protein and Peptide drug delivery: a special emphasis on polymeric nanoparticles. Protein Pept Lett, 2014. 21(11): p. 110220.

134. Johnson, O.L., et al., A month-long effect from a single injection of microencapsulated human growth hormone. Nat Med, 1996. 2(7): p. 795-9.

135. Khang, G., et al., Preparation and characterization of Japanese encephalitis virus vaccine loaded poly(L-lactide-co-glycolide) microspheres for oral immunization. Biomed Mater Eng, 1999. 9(1): p. 49-59.

136. Fattal, E., P. Couvreur, and S. Pecquet, [Oral tolerance induced by poly (lactideco-glycolide) containing B lactoglobulin]. Ann Pharm Fr, 2002. 60(1): p. 44-9.

137. Perez, C., et al., Recent trends in stabilizing protein structure upon encapsulation and release from bioerodible polymers. J Pharm Pharmacol, 2002. 54(3): p. 30113.

138. Yeh, M.K., The stability of insulin in biodegradable microparticles based on blends of lactide polymers and polyethylene glycol. J Microencapsul, 2000. 17(6): p. 743-56.

139. Mathiowitz, E., et al., Biologically erodable microspheres as potential oral drug delivery systems. Nature, 1997. 386(6623): p. 410-4. 
140. Milstein, S.J., et al., pH-dependent microspheres from modified soybean protein hydrolysate. J Microencapsul, 1996. 13(6): p. 651-65.

141. Zhang, Y., et al., Preparation and evaluation of alginate-chitosan microspheres for oral delivery of insulin. Eur J Pharm Biopharm, 2011. 77(1): p. 11-9.

142. Lai, S.K., et al., Rapid transport of large polymeric nanoparticles in fresh undiluted human mucus. Proceedings of the National Academy of Sciences, 2007. 104(5): p. 1482-1487.

143. Allen, T.M. and P.R. Cullis, Drug delivery systems: entering the mainstream. Science, 2004. 303(5665): p. 1818-22.

144. Dawson, M., D. Wirtz, and J. Hanes, Enhanced viscoelasticity of human cystic fibrotic sputum correlates with increasing microheterogeneity in particle transport. J Biol Chem, 2003. 278(50): p. 50393-401.

145. Suh, J., M. Dawson, and J. Hanes, Real-time multiple-particle tracking: applications to drug and gene delivery. Adv Drug Deliv Rev, 2005. 57(1): p. 6378.

146. Rekha, M.R. and C.P. Sharma, Chapter 8 - Nanoparticle Mediated Oral Delivery of Peptides and Proteins: Challenges and Perspectives, in Peptide and Protein Delivery, C. Van Der Walle, Editor. 2011, Academic Press: Boston. p. 165-194.

147. Sarmento, B., et al., Alginate/chitosan nanoparticles are effective for oral insulin delivery. Pharm Res, 2007. 24(12): p. 2198-206.

148. Chan, J.M., et al., Polymeric nanoparticles for drug delivery. Methods Mol Biol, 2010. 624: p. 163-75.

149. Russell-Jones, G.J., Use of targeting agents to increase uptake and localization of drugs to the intestinal epithelium. J Drug Target, 2004. 12(2): p. 113-23.

150. Dmitry, M., et al., Oral Delivery of Insulin with the eligen(\&\#174;) Technology: Mechanistic Studies. Current Drug Delivery, 2005. 2(2): p. 191-197.

151. Hoffman, A. and B. Qadri, Eligen insulin--a system for the oral delivery of insulin for diabetes. IDrugs, 2008. 11(6): p. 433-41.

152. St Clair, N., Y.F. Wang, and A.L. Margolin, Cofactor-Bound Cross-Linked Enzyme Crystals (CLEC) of Alcohol Dehydrogenase. Angew Chem Int Ed Engl, 2000. 39(2): p. 380-383.

153. Verma, D., et al., Protein Based Nanostructures for Drug Delivery. J Pharm (Cairo), 2018. 2018: p. 9285854.

154. Morcol, T., et al., Calcium phosphate-PEG-insulin-casein (CAPIC) particles as oral delivery systems for insulin. Int J Pharm, 2004. 277(1-2): p. 91-7.

155. https://www.drugdevelopment-technology.com/projects/oral-lyn/.

156. https://generex.com/index.html.

157. Clement, S., et al., Oral Insulin Product Hexyl-Insulin Monoconjugate 2 (HIM2) in Type 1 Diabetes Mellitus: The Glucose Stabilization Effects of HIM2. Diabetes Technology \& Therapeutics, 2002. 4(4): p. 459-466.

158. Cefalu, W.T., Concept, Strategies, and Feasibility of Noninvasive Insulin Delivery. Diabetes Care, 2004. 27(1): p. 239-246.

159. Russell-Jones, G.J., et al., Synthesis of LHRH antagonists suitable for oral administration via the vitamin B12 uptake system. Bioconjug Chem, 1995. 6(1): p. 34-42. 
160. Petrus, A.K., et al., Vitamin B12 as a carrier for the oral delivery of insulin. ChemMedChem, 2007. 2(12): p. 1717-21.

161. Faria, A.M. and H.L. Weiner, Oral tolerance: therapeutic implications for autoimmune diseases. Clin Dev Immunol, 2006. 13(2-4): p. 143-57.

162. www.autoimmuneinc.com/.

163. He, H., et al., Adapting liposomes for oral drug delivery. Acta Pharmaceutica Sinica B, 2019. 9(1): p. 36-48.

164. Langer, R., Drug delivery and targeting. Nature, 1998. 392(6679 Suppl): p. 5-10.

165. https://www.pharmaceutical-technology.com/contractors/drug delivery/merrionpharma/.

166. https://clinicaltrials.gov/ct2/show/NCT01931137?term=GIPET\&rank=4.

167. Philippart, M., J. Schmidt, and B. Bittner, Oral Delivery of Therapeutic Proteins and Peptides: An Overview of Current Technologies and Recommendations for Bridging from Approved Intravenous or Subcutaneous Administration to Novel Oral Regimens. Drug Res (Stuttg), 2016. 66(3): p. 113-20.

168. https://clinicaltrials.gov/ct2/show/NCT02535715?term=Oramed\&rank=1.

169. https://enterisbiopharma.com/wp-content/uploads/2018/09/enteris-biopharmabrochure-9-20-18.pdf.

170. Buchanan, A. and J.D. Revell, Chapter 8 - Novel Therapeutic Proteins and Peptides, in Novel Approaches and Strategies for Biologics, Vaccines and Cancer Therapies, M. Singh and M. Salnikova, Editors. 2015, Academic Press: San Diego. p. 171-197. 


\section{VITA}

Nirnoy Dan was born in Burdwan, West Bengal, India in 1993. He graduated with Bachelor of Pharmacy degree in 2016 from Birla Institute of Technology, Mesra, Ranchi. Nirnoy joined Department of Pharmaceutical Sciences at The University of Tennessee Health Science Center as a graduate student in Aug 2016. He anticipates completion of the requirements for his Master of Science degree in Pharmaceutical Sciences with a focus on Pharmaceutics in Dec 2019 